\title{
Recent Advancements in the Understanding of the Surface Chemistry in $\mathrm{TiO}_{2}$ Photocatalysis
}

\author{
Alexander V. Vorontsov ${ }^{1, *}$, Héctor Valdés ${ }^{2}$, Panagiotis G. Smirniotis ${ }^{3}$ and Yaron Paz ${ }^{1}$ \\ 1 Technion-Israel Institute of Technology, The Wolfson Department of Chemical Engineering, Technion City, \\ Haifa 3200003, Israel; paz@technion.ac.il \\ 2 Laboratorio de Tecnologías Limpias, Facultad de Ingeniería, Universidad Católica de la Santísima \\ Concepción, Alonso de Ribera, Concepción 2850, Chile; hvaldes@ucsc.cl \\ 3 Chemical Engineering, University of Cincinnati, Cincinnati, OH 45221-0012, USA; \\ Panagiotis.Smirniotis@uc.edu \\ * Correspondence: a-voronts@yandex.ru; Tel.: +972-53-892-6081
}

Received: 30 November 2019; Accepted: 22 January 2020; Published: 18 February 2020

check for updates

\begin{abstract}
Surface chemistry plays a major role in photocatalytic and photoelectrochemical processes taking place with the participation of $\mathrm{TiO}_{2}$. The synthesis methods, surface characterizations, theoretical research methods, and hardware over the last decade generated opportunities for progress in the surface science of this photocatalyst. Very recently, attention was paid to the design of photocatalysts at the nanoscale level by adjusting the types of exposed surfaces and their ratio, the composition and the surface structure of nanoparticles, and that of individual surfaces. The current theoretical methods provide highly detailed designs that can be embodied experimentally. The present review article describes the progress in the surface science of $\mathrm{TiO}_{2}$ and $\mathrm{TiO}_{2}$-based photocatalysts obtained over the last three years. Such aspects including the properties of macro- and nano-scale surfaces, noble-metal-loaded surfaces, doping with $\mathrm{Mg}$ and S, intrinsic defects (oxygen vacancies), adsorption, and photoreactions are considered. The main focus of the article is on the anatase phase of $\mathrm{TiO}_{2}$.
\end{abstract}

Keywords: anatase surfaces; aspect ratio; adsorption; surface heterogeneity; nanosheets; metal loading; doping; oxygen vacancies; photoreactions

\section{Introduction}

Titanium dioxide has multiple applications in the areas of catalysis, photocatalysis, electrocatalysis, adsorption, photovoltaics, and sensing [1,2], in addition to many others. Its annual production is around 10 million tons owing to its use as a white pigment. Its unique properties of high chemical stability and activity in photocatalytic processes made it a subject of intensive scientific research over the last half-century.

Titanium dioxide exists in its three main phases-rutile, anatase, and brookite. Furthermore, there are several other rarely obtained phases such as $\mathrm{TiO}_{2} \mathrm{~B}$. All the crystal phases of $\mathrm{TiO}_{2}$ exhibit photochemical activity. However, the anatase phase usually possesses the best photocatalytic properties. Mixed phases, for example, the well-known rutile-anatase mixture P25 powder, have a high activity due to the existence of heterojunctions and the separation of photogenerated electron-hole pairs [3].

$\mathrm{TiO}_{2}$ drives all classes of photocatalytic and photoelectrocatalytic processes under proper conditions. When applied for the abatement of pollutants, both adsorption and photodegradation contribute to the media purification [4]. Due to the formation of very stable surface complexes with polyvalent anions, adsorption is an efficient water purification method from $\mathrm{Cr}(\mathrm{VI}), \mathrm{V}(\mathrm{V}), \mathrm{Bi}(\mathrm{III})$, 
and $\mathrm{As}(\mathrm{V})$ [5]. For the purely adsorptive purification, $\mathrm{TiO}_{2}$ should be preferably in amorphous hydrous form.

While rutile was the subject of surface science research for a long time, anatase became the subject of intensive interest only recently, following the developing of preparation methods that allowed the controlling of its shape. Anatase exposes mainly (101), (001), and (100) surfaces in its crystals. In relations between nanoparticles, shapes, and photocatalytic activity, there is a general consensus that nanoparticles with a large number of (001) facets have a higher activity than nanoparticles comprising (100) facets or (101) facets [6], whereas the photocurrent density is the highest for (100) facets. It seems that the effect of the surface structure on photoactivity is substrate- and reaction- sensitive. Therefore, it is desirable to develop understanding and prediction methods for selecting proper shapes and exposed facets for a given process and substrate. Recently, Peng and Tsang [7] summarized faceting effects in $\mathrm{TiO}_{2}$ and $\mathrm{ZnO}$ in relation to photocatalysis. In light of the large number of published manuscripts, this review concentrates on the progress obtained over the last three years.

\section{The Surface Structure of Bulk $\mathrm{TiO}_{2}$}

The structure and properties of different surfaces of $\mathrm{TiO}_{2}$ are of great importance for designing highly active photocatalysts and solar cells. The development of means which enable the preparation of $\mathrm{TiO}_{2}$ particles with controlled facets facilitated the integration of theory and experiments when studying the $\mathrm{TiO}_{2}$ surfaces. The study of structures of the most often obtained surfaces, such as (101) and (001), also attracted significant interest. The (001) surface is regularly considered as the most reactive one for dark and photoreactions. Recently, its structure was investigated theoretically by Shi et al. [8] using a PBE GGA functional, with an emphasis on surface stress effects. The unreconstructed clean (001) surface shown in Figure 1a has a very high anisotropic stress, with the stress tensor component along (100) equal to $-29.7 \mathrm{kbar}$ and that along (010) equal to $-35.6 \mathrm{kbar}$. In order to reduce this stress, the surface undergoes reconstruction with the formation of an additional ridge of atoms every fourth unit cell, as shown in Figure 1b,c. The reconstructed surface has just a -1.2-kbar stress tensor component in the (100) direction. However, the stress in the (010) direction was not reduced. Therefore, it was suggested that this stress can be released by creating vacancies in the ridge atoms. This approach was evaluated, but the effect of such defects on the stress in the ridge was found to be minor.
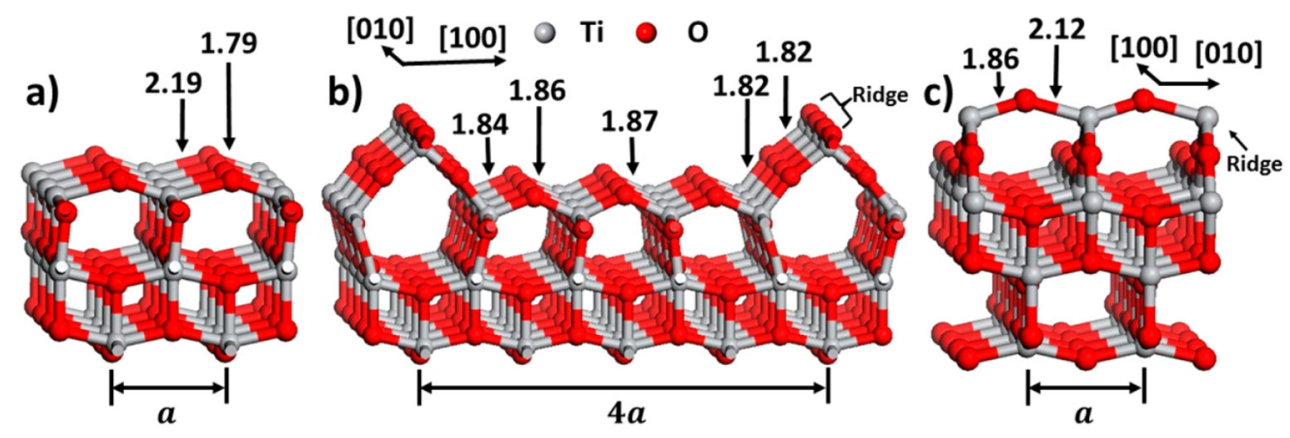

Figure 1. The structure of a pristine $(\mathbf{a}),(1 \times 4)$ reconstructed $(\mathbf{b})$, and $(001)(\mathbf{c})$ anatase surface. Reprinted with permission from Reference [8]; copyright (2017) American Chemical Society.

Oxygen vacancies that are often present in the surfaces of $\mathrm{TiO}_{2}$ and in the bulk give rise to states at approximately $1 \mathrm{eV}$ below the Fermi level [9]. Theoretical methods resulted in a large scattering of values for the location of these states (from 0.1 to $1.8 \mathrm{eV}$ below the conduction band), mostly reflecting differences in the applied computational methods. Therefore, additional experimental data are required for anatase and rutile surfaces for shedding light on the real state levels of oxygen vacancies.

A recent review by Fujishima et al. [10] summarized the literature data on defects in bulky $\mathrm{TiO}_{2}$ surfaces such as oxygen vacancies, hydroxyl groups, interstitial Ti atoms, and Ti vacancies, as well as on the surface electron and hole polarons. Thus, we do not consider these questions in the present 
review. Another comprehensive review of the role of defects in photocatalysis, which overviews not only titanium dioxide but also other photocatalysts such as $\mathrm{ZnO}, \mathrm{Co}_{3} \mathrm{O}_{4}, \mathrm{ZnS}, \mathrm{BiO}_{2}, \mathrm{WO}_{3}, \mathrm{BiOCl}$, and many more, may assist readers whose interest extends beyond $\mathrm{TiO}_{2}$ [11].

\section{The Structure of the Surfaces of $\mathrm{TiO}_{2}$ Nanoparticles}

Nanoparticles are particles with typical sizes lower than $100 \mathrm{~nm}$ in one, two, or all three dimensions. As the typical size is reduced, the role of edges and vertices becomes more and more important in determining the properties of the particles. The properties of nanoparticles were the subject of research for quite a long time. However, only after modern computational methods and hardware were developed to the proper level did it become possible to investigate nanoparticles with a realistic size of $1 \mathrm{~nm}$ and larger in an accurate manner.

Among the nanoparticles of $\mathrm{TiO}_{2}$ of all sizes, nanoparticles with one, two, or all three dimensions below $10 \mathrm{~nm}$ are of special interest since size effects are clearly present at such sizes. Prominently, computational models resulted in $\mathrm{TiO}_{2}$ nanoparticle structures that were in agreement with experimental observations, i.e., the crystalline core was surrounded by a few layers of amorphous atoms [12]. Here, the PM6 semiempirical method was found to be advantageous for modeling $\mathrm{TiO}_{2}$ compared to the newer method PM7.

Recently, the structure and locations of photogenerated charge carriers in decahedral anatase nanoparticles were the subject of intensive computational research. Fazio et al. [13] studied two decahedral nanoparticles and a spherical anatase nanoparticle, shown in Figure 2a, using the hybrid functionals B3LYP and HSE06. They obtained triplet excited states and the locations of electrons and holes in each of these nanoparticles. Figure $2 b, c$ demonstrate the spin density of a hole and an electron, respectively. The hole tends to be localized over oxygen atoms in the middle layers and over oxygens around $(101) /(101) /(101) /(101)$ corners. The electron is localized over titanium atoms in the central part.

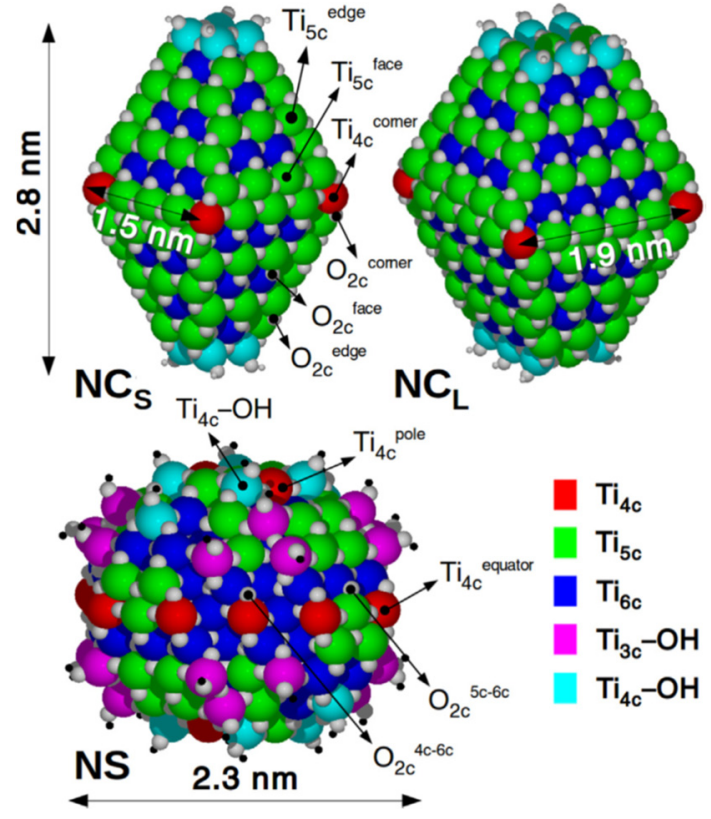

(a)

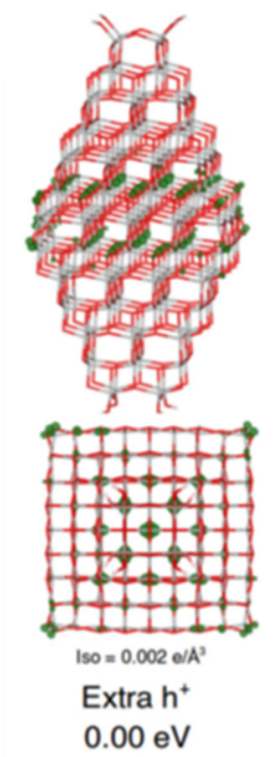

(b)

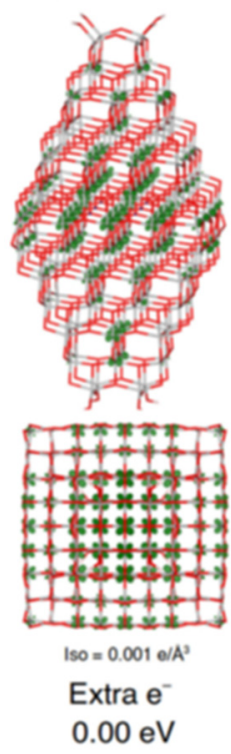

(c)

Figure 2. (a) The structure of the anatase nanoparticles $\mathrm{NC}_{\mathrm{S}}\left(\mathrm{TiO}_{2}\right)_{159}\left(\mathrm{H}_{2} \mathrm{O}\right)_{4}, \mathrm{NC}_{\mathrm{L}}\left(\mathrm{TiO}_{2}\right)_{260}\left(\mathrm{H}_{2} \mathrm{O}\right)_{6}$, and NS $\left(\mathrm{TiO}_{2}\right)_{223}$. (b) Spin density of an extra hole in the $\mathrm{NC}_{\mathrm{S}}$ nanoparticle. (c) Spin density of an extra electron in this nanoparticle. Reprinted with permission from Reference [13]; copyright (2016) Elsevier.

These results are in a good accord with the results obtained for smaller decahedral anatase nanoparticles with exposed (001) and (101) facets [14]. Here, nanoparticles of different size and different content of surface hydroxyl groups at the (001)/(101) edges and vertices between the four adjacent 
(101) surfaces were constructed. It was found that the positions of untrapped electrons and holes depended on the distribution of surface $\mathrm{OH}$ groups in such small nanoparticles. As in the previous example, holes tended to localize in the central parts of the particle and electrons localized over the whole nanoparticles or over (001) facets.

It was demonstrated recently that the surface of anatase $\mathrm{TiO}_{2}$ nanoparticles smaller than $2 \mathrm{~nm}$ possesses inherent heterogeneity in the acidity strength of the adsorption sites [15]. A CO molecule was adsorbed on all possible Ti atoms in exposed (001), (100), and (010) facets of the anatase nanoparticles. A small increase in the area of the (001) surface resulted in average $\mathrm{CO}$ adsorption enthalpy decrease by about $10 \mathrm{~kJ} / \mathrm{mol}$. Adsorption over (100) and (010) surfaces was stronger $\left(\Delta H_{\mathrm{ads}}=-131\right.$ to $\left.-138 \mathrm{~kJ} / \mathrm{mol}\right)$ than adsorption over the (001) surface $\left(\Delta H_{\text {ads }}=-76\right.$ to $\left.-95 \mathrm{~kJ} / \mathrm{mol}\right)$. It is interesting that adsorption over the edges between (100) or (010) surfaces and (001) was as strong as over (100) surfaces, while adsorption over the edges between (100) surfaces and (010) surfaces was somewhat weaker $\left(\Delta H_{\mathrm{ads}}=-126 \mathrm{~kJ} / \mathrm{mol}\right)$. The energy of $\mathrm{CO}$ adsorption is known to correlate with the strength of surface Lewis sites and with the infrared band frequency of adsorbed $\mathrm{CO}$. Stronger acid sites have larger adsorption energy and lower CO vibration frequency. Thus, the (100) and the (010) surfaces are the strongest Lewis acid catalysts. The sites over (100) or (010) surfaces near the vertices possess the highest CO adsorption energy and the strongest Lewis acidity.

Lamiel-Garcia et al. [16] theoretically studied anatase nanoparticles of octahedral and decahedral shapes exposing (101) and (001) surfaces, with size up to $6 \mathrm{~nm}$ and formulas of $\left(\mathrm{TiO}_{2}\right)_{10}-\left(\mathrm{TiO}_{2}\right)_{455}$. The energy of formation per $\mathrm{TiO}_{2}$ unit and the band gap, as well as variations of other parameters, were studied with PBE, PBEx, and PBE0 functionals. The presence of quantum-size effects was noted for all nanoparticles, and it was predicted that bulk-like properties would be obtained at typical dimensions larger than approximately $20 \mathrm{~nm}$.

Selli et al. [17] modeled spherically shaped $\mathrm{TiO}_{2}$ nanoparticles containing 300 to 4000 atoms. They compared the precision of computations carried out using the semiempirical method DFTB (matsci-0-3 parameters set) versus the traditionally used B3LYP hybrid functional. Similar results were obtained by all three methods (DFTB, PBE, and B3LYP). Simulating the annealing of the nanoparticles resulted in spherical shapes, 1.5 to $4.4 \mathrm{~nm}$ in diameter. The well-faceted decahedral nanoparticles expected according to the Wulff construction were not formed, probably because of the small duration of the annealing process (less than $45 \mathrm{ps}$ ).

Results obtained by the DFTB method indicated a quantum-size effect for particles, 1.5-3.0 nm in diameter. In contrast, DFT B3LYP computations yielded a steady decrease in the bandgap for all diameters. According to the results of this study, the DFTB method is recommended since it provides satisfactory precision and high computation speed. Investigation on photogenerated charges revealed that electrons and holes, trapped at the surface or at the subsurface of the photocatalyst, have considerably larger stability $(-0.79 \mathrm{eV})$ compared with the vertical triplet state that can be considered as unbound exciton [18]. In another recent study [19], the optical band gap was theoretically investigated for nanoparticles containing 1-84 $\mathrm{TiO}_{2}$ units. It was found that the band gap was essentially the same for particles containing more than four $\mathrm{TiO}_{2}$ units. This possibly reflects the fact that the band gap in these particles is determined by the surface states, which are size-independent in contrast to most cases where the bandgap is determined by the bulk and, hence, it is size-dependent. Another reason for the scattering in the results could be the use of particles that differed in their shapes. Both hypotheses were confirmed in another recent study [20], which considered decahedral anatase nanoparticles of different shape and with different surface groups. The quantum-size effect was present within each group of nanoparticles of specific shape but constant contribution of surface states. However, the locations of photogenerated holes and electrons were seldom in agreement with the experimental data.

Le and Schweigert investigated the interfaces between two decahedral anatase nanoparticles of $\left(\mathrm{TiO}_{2}\right)_{70}\left(\mathrm{H}_{2} \mathrm{O}\right)_{2}$ connected together via their (001) facets or via (101) facets [21]. They found that the deep trap states could be localized at the interfaces between two nanoparticles due to local structure 
deformations. Interestingly, they also found that some of (001)/(101) edges were hydroxylated in the course of geometry optimization; the result was consistent with the higher stability of such nanoparticles [14].

Oxygen vacancies $\left(V_{O}\right)$ are inherent defects in titanium dioxide and exert influence on its properties. A number of recent theoretical studies were devoted to $V_{O}$ in nanoparticles. A complete set of $V_{O}$ was studied in Reference [22] for a decahedral anatase nanoparticle $\left(\mathrm{TiO}_{2}\right)_{121}\left(\mathrm{H}_{2} \mathrm{O}\right)_{6}$ having $\mathrm{OH}$ groups at (001)/(101) edges. Vacancies were found to be more stable in (101) surface compared to (001) facet. The most stable vacancies were in the subsurface layer of atoms of (101) facet closer to the vertices between four adjacent (101) facets. Morales-García et al. [23] studied oxygen vacancies in an octahedral anatase $\left(\mathrm{TiO}_{2}\right)_{84}$ nanoparticle with a length of $3 \mathrm{~nm}$, exposing (101) facets only, as shown in Figure 3 . The functionals PBE, PBEx, and PBE0 were used for the computations, and the relative stability of $\mathrm{V}_{\mathrm{O}}$ was different for these functionals. The most easily formed vacancies were at the top vertex (T1) and possibly in the bulk (I-3-2) (Figure 3).

(b)

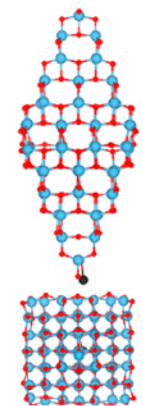

$\mathrm{T}-1$

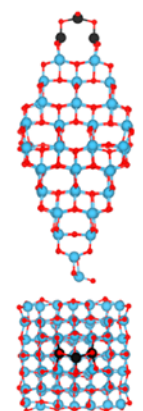

I-3-1 (a)

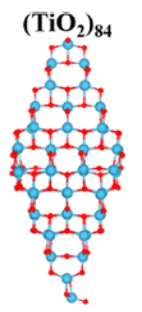

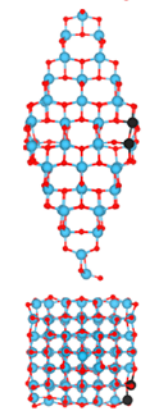

E-2

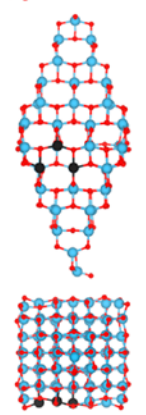

F-3

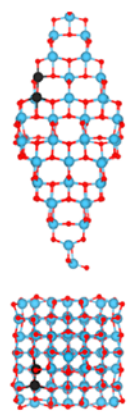

F-2

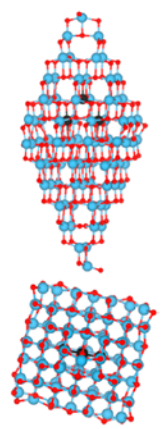

I-3-2

Figure 3. The $\left(\mathrm{TiO}_{2}\right)_{84}$ anatase nanoparticle of $3 \mathrm{~nm}$ size with (101) facets (a) and oxygen vacancies in it (b). Reproduced from Reference [23] with permission; copyright (2018) American Chemical Society.

Morita and Yasuoka reported a thorough study on $\mathrm{V}_{\mathrm{O}}$ and interstitial Ti in octahedral nanoparticles $\left(\mathrm{TiO}_{2}\right)_{35}$ and $\left(\mathrm{TiO}_{2}\right)_{165}$ using PBE $+\mathrm{U}\left(\mathrm{U}_{\text {eff }}=3.3 \mathrm{eV}\right)$ and HSE06 approaches [24]. The most stable $\mathrm{V}_{\mathrm{O}}$ s were found in the subsurface layer of atoms and at the tip, in agreement with previous study results. The oxygen vacancies correspond to deep traps of $>1 \mathrm{eV}$ below the conductance band. Using semiempirical computations, it was found that $\mathrm{V}_{\mathrm{O}}$ s are easier to be formed in smaller anatase decahedral nanoparticles [25]. Three types of structures were found following the formation of $V_{O}$, namely, (1) repulsion of surrounding Ti atoms, (2) transfer of oxygen vacancy to a neighbor site, and (3) transformation of vacancy into Magneli phase.

Experimentally produced $\mathrm{TiO}_{2}$ was found to have amorphous surface layers, 2-6 nm in thickness following hydrogenetaion. The amorphous layers were attributed to reduced and $\mathrm{H}$-doped defective structures [26]. These layers are beneficial for the photocatalytic hydrogen production reaction.

The problems of finding the most stable shapes and sizes of $\mathrm{TiO}_{2}$ nanoparticles, the effect of oxygen vacancies, and the presence of quantum-size effects were addressed in many theoretical studies, and the results were partially summarized in a recent review [27] covering research up to 2017. Surprisingly, 
despite the expectation for a strong effect of the surface groups on these properties, such a strong effect was not echoed in the cumulative literature.

\section{The Surface Structure of Two-Dimensional (2D) $\mathrm{TiO}_{2}$}

Nanoparticles having high predominance of just one facet are often called nanoblankets (nanosheets) since only one facet is actually present. Such nanoblankets can serve as very efficient materials for photocatalysis [28] and sensors since the fraction of the active surface is very high. Recently, it was demonstrated that the sensing properties of (001)-faceted anatase nanoblankets can be further improved by reductive treatment [29]. The resistivity response to vapors of ethanol, acetone, triethylamine, and formaldehyde increases dramatically, testifying for the adequacy of this treatment for sensing applications.

A special class of $\mathrm{TiO}_{2}$ nanoblankets is represented by extremely thin sheets containing several layers of atoms. Such nanosheets are rarely prepared experimentally but could become of high interest in the near future. Intensive theoretical studies revealed some interesting properties of these very thin nanosheets. The thinnest nanosheets contain just a single layer of $\mathrm{Ti}$ and $\mathrm{O}$ atoms. However, such monolayer nanosheets are not stable, at least for (010) and (101) surfaces [30]. Their structure becomes strongly distorted, and they are converted into the same lepidocrocite structure. Such lepidocrocite titanates have an orthorhombic structure and formulas of $\mathrm{H}_{2} \mathrm{Ti}_{4} \mathrm{O}_{9}$, $\mathrm{H}_{2} \mathrm{Ti}_{5} \mathrm{O}_{11}$, and so on. These nanosheets have a thickness of $0.7 \mathrm{~nm}$ and demonstrate stable activity in hydrogen evolution [31]. Moreover, such "monolayer" nanosheets with a thickness of $1.2 \mathrm{~nm}$ were found to be more active under visible light in the oxidation of furfuryl alcohol to furfuraldehyde compared to more bulky sheets [32].

If a larger number of atomic layers are taken to construct a nanosheet, it becomes stable. Liu et al. [33] investigated (010) anatase nanosheets containing three to seven layers of atoms. There was a quantum-size effect, as the band gap increased when the thickness of the nanosheet decreased. The thinnest nanosheet possessed the highest conduction band minimum, which is considered beneficial for the photocatalytic reactions. Gao et al. [34] experimentally prepared very small nanoplates with 4-5 nm lateral size and $0.5 \mathrm{~nm}$ thickness (Figure 4). Their X-ray diffraction (XRD) pattern showed only the (002) peak attributed to anatase. Unfortunately, no further details on properties such as band-gap values and chemical composition were reported.

\section{$0.5 \mathrm{~nm}$}

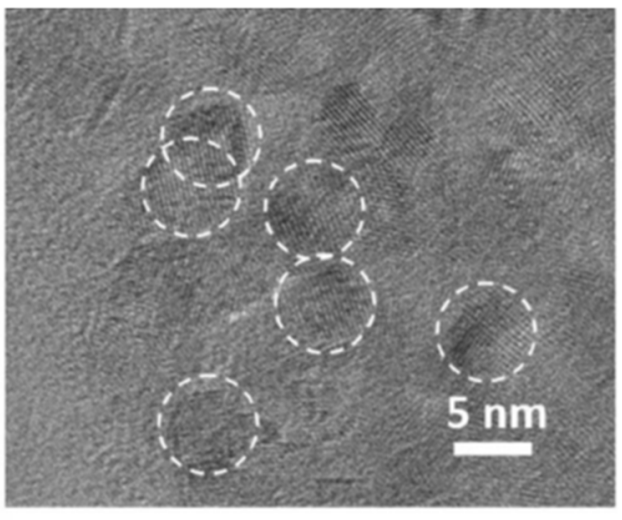

(a)

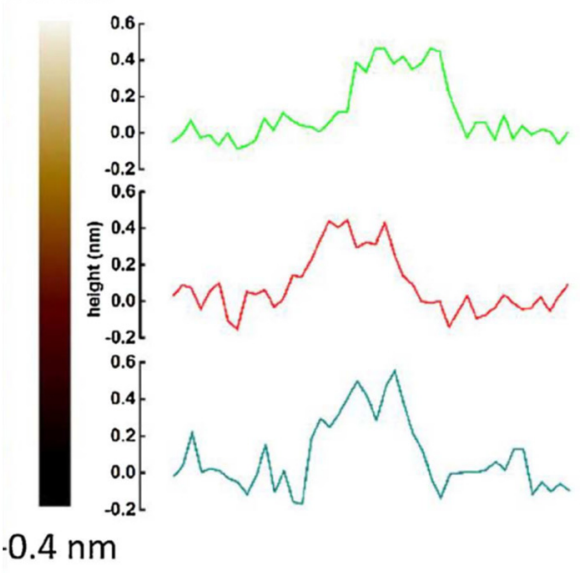

(b)

Figure 4. Experimentally prepared extremely small titania nanosheets: (a) high-resolution transmission electron microscopy (HR-TEM) image; The white circles indicate the presence of specific nanosheets (b) atomic force microscopy (AFM) thickness profile, showing the height of three particles. Reproduced from Reference [34] with permission; copyright (2017) Elsevier. 
Hence, these properties were studied theoretically for the thinnest possible nanoblankets containing just two layers of Ti atoms of rectangular [35] and square shapes [36]. It turned out that the quantum-size effect was present in the square-shaped nanosheets but was obscured in the nanoribbons due to their smaller thickness. The surface of the nanosheet can be fully flat for small nanosheets having an even number of atomic layers, but it is curved for nanosheets with an odd number of layers. In any case, the extent of hydroxylation at the edges seems to be more important than the size effect in the value of the band gap.

Wang et al. [37] using DFT computations predicted four different phases of $\mathrm{TiO}_{2}$ containing two layers of Ti atoms, named $\alpha-2 \mathrm{D}-\mathrm{TiO}_{2}$ to $\delta-2 \mathrm{D}-\mathrm{TiO}_{2}$, with the $\alpha$-phase being the most stable. The anatase structure corresponds to the $\beta$-phase, which is slightly less stable. They also investigated oxygen vacancies in the most stable lepidocrocite-like phase and found that the unpaired electrons reside entirely over the Ti atoms adjacent to the vacancy in the ferromagnetic (triplet) state, a result in full agreement with recent semiempirical studies [22].

\section{Metal-Loaded $\mathrm{TiO}_{2}$ Surfaces}

Loading of noble metals over the surfaces of titanium dioxide is an important method to improve photocatalytic activity via improvement of separation of photogenerated charges [38], decreasing energy barriers for reactions such as hydrogen production from water [39], spillover to the photocatalyst [40], and prevention of deactivation [41]. Experimentally, metal loading is carried out via a number of techniques including photodeposition [42,43], chemical reduction [44], and sputtering [45]. The first of these methods was suggested to result in selective loading of metal nanoparticles over (101) surfaces of decahedral anatase nanoparticles. However, careful consideration of transmission electron microscopy (TEM) and high-resolution (HR) TEM images of such loaded materials (Figure 5) does not lead to evident conclusion that only (101) surfaces are loaded and (001) surfaces are completely free from the metal nanoparticles. The latter method results in nonselective deposition of metal particles over $\mathrm{TiO}_{2}$ surfaces.

$\mathrm{Li}$ et al. [46] constructed the simplest model of platinized $\mathrm{TiO}_{2}$ by attaching a single $\mathrm{Pt}$ atom over the (001) surface. The Pt atom was bound to Ti and O atoms, forming $2.62 \AA \mathrm{Pt}-\mathrm{Ti}$ and $2.05 \AA \mathrm{Pt}-\mathrm{O}$ bonds. This structure undergoes strong changes as a result of chemisorption of molecular oxygen, hydroxyl group, or $\mathrm{HCHO}$ over the Pt atom or its surroundings. The strong changes might not be present in real $\mathrm{Pt} / \mathrm{TiO}_{2}$ catalysts because platinum is rarely loaded in the form of single atoms.

Schlexer et al. [47] used more advanced models containing 10 atoms of $\mathrm{Ru}$ or $\mathrm{Cu}$ attached to the (101) surface of anatase. The adsorption energy for the $\mathrm{Ru}_{10}$ and $\mathrm{Cu}_{10}$ clusters was found to be -735 and $-350 \mathrm{~kJ} / \mathrm{mol}$, respectively, for stoichiometric $\mathrm{TiO}_{2}$. Adsorption of $\mathrm{CO}_{2}$ over the metal clusters resulted in some moderate changes in the structure of the metal clusters and their binding to the (101) surface. Adsorption results in $\mathrm{CO}_{2}$ dissociation into adsorbed $\mathrm{CO}$ and $\mathrm{O}$ with a barrier of $+76 \mathrm{~kJ} / \mathrm{mol}$ for $\mathrm{Ru}_{10} / \mathrm{TiO}_{2}$. The presence of an oxygen vacancy at the periphery of the metal cluster leads to the stronger molecular adsorption of $\mathrm{CO}_{2}$.

Schvval at el. [48] developed models consisting of $\mathrm{Ag}_{4}$ clusters, attached to rutile (110) and to anatase (101) surfaces. Tetrahedral configuration of the cluster was found to be the most stable according to the DFT $+\mathrm{U}$ method used. The clusters were attached to oxygen atoms and injected charge into the $\mathrm{TiO}_{2}$ surfaces.

A DFT + U-D3 investigation on the $\mathrm{Pt}_{4} /$ graphene and $\mathrm{Pt}_{4} /$ anatase (101) surfaces was reported recently and showed that the $\mathrm{Pt}_{4} /$ anatase material dissociates hydrogen almost without a barrier and there is spillover of formed hydrogen atoms onto the $\mathrm{TiO}_{2}$ surface. The spillover results in the formation of surface $\mathrm{OH}$ groups.

$\mathrm{Cu}$-loaded anatase particles are a good photocatalyst for $\mathrm{CO}_{2}$ photoreduction with formation of $\mathrm{CO}$ [49]. A theoretical model was suggested for the photocatalytic cycle on $\mathrm{Cu}$-loaded (101) surface of anatase, in which $\mathrm{CO}_{2}$ adsorption at the $\mathrm{Cu}_{4}-\mathrm{TiO}_{2}$ interface is strong $\left(\Delta H_{\mathrm{ads}}=-126 \mathrm{~kJ} / \mathrm{mol}\right)$ with 
formation of carbonate. The most endothermic step is CO desorption $\left(\Delta H_{\mathrm{r}}=+314 \mathrm{~kJ} / \mathrm{mol}\right)$. Cu-loaded $\mathrm{TiO}_{2}$ is a cost-efficient alternative to Pt-loaded $\mathrm{TiO}_{2}$, which photoreduces $\mathrm{CO}_{2}$ into $\mathrm{CO}$ and $\mathrm{CH}_{4}$ [44].

$\mathrm{Li}$ et al. prepared anatase nanoparticles with a very high fraction of highly active (001) facets doped with fluoride anions [50]. After loading with $\mathrm{Pt}$, these nanosheets demonstrated a quantum efficiency of $34 \%$ in hydrogen production, a rather high value. Introduction of oxygen vacancies (Vo) into the $\mathrm{TiO}_{2}$ support improved the reductive properties of deposited $\mathrm{Pd}$ nanoparticles [51]. $\mathrm{V}_{\mathrm{O}}$ were introduced into $\mathrm{TiO}_{2}$ via calcination at $800^{\circ} \mathrm{C}$ in Ar flow. As a result of the presence of $\mathrm{V}_{\mathrm{O}}$, the rate of electron transfer to adsorbed oxygen molecules increased significantly. The effect was attributed to the injection of electrons from the vacancies into the Pd nanoparticles, thus increasing the electron density required for the reaction. Similar effects were also applicable for photocatalytic reactions over metal-loaded $\mathrm{TiO}_{2}$ having oxygen vacancies.
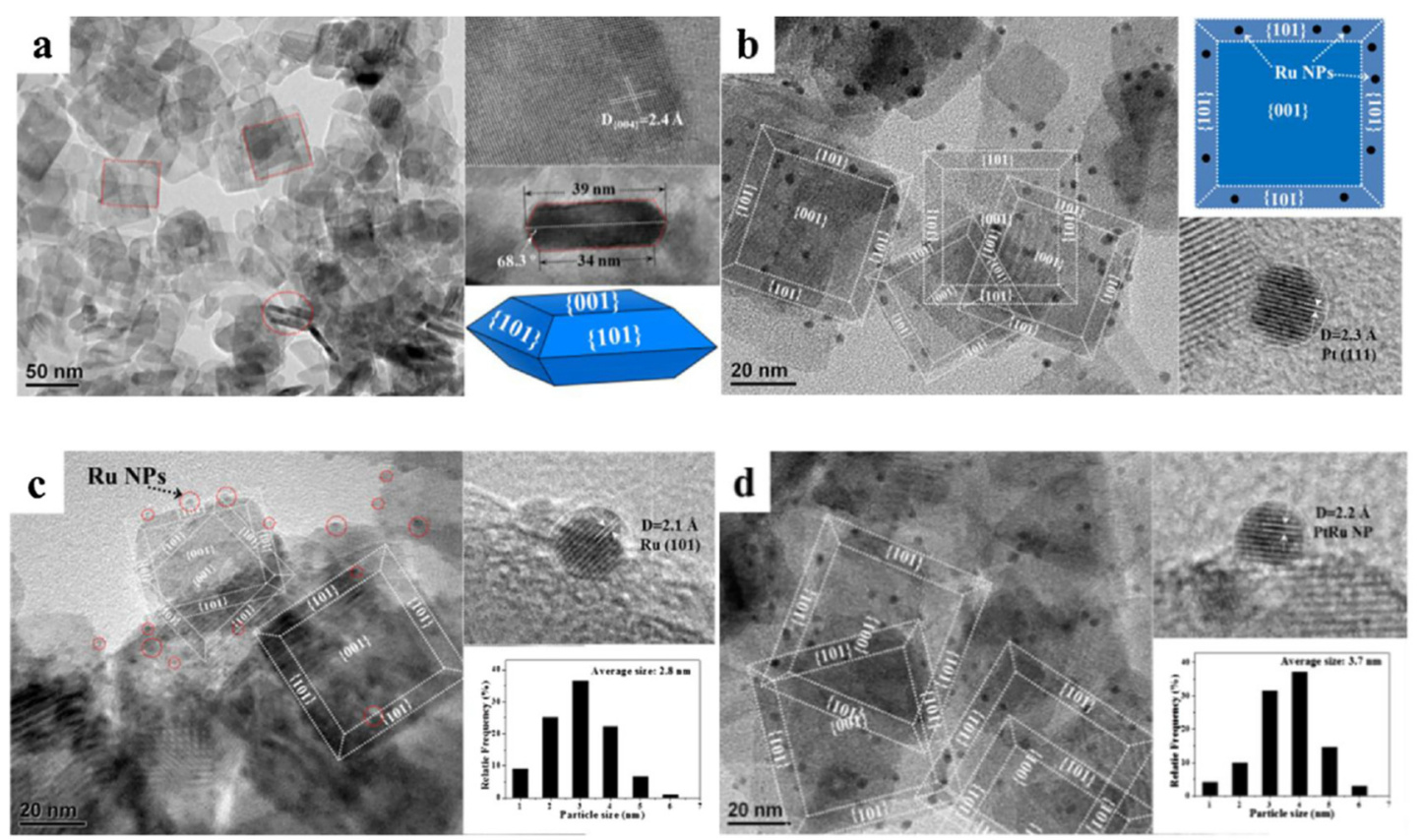

Figure 5. Microscopic images of anatase nanoparticles (a), of anatase nanoparticles loaded with $\mathrm{Pt}(\mathbf{b})$, with $\mathrm{Ru}(\mathbf{c})$, and with PtRu, and (d) using photodeposition. The insets in $(\mathbf{a}, \mathbf{b})$ represent the shape of the nanoparticles. The insets in (c,d) represent the size distribution. Reproduced from Reference [43] with permission; copyright (2018) Elsevier.

\section{Adsorption over $\mathrm{TiO}_{2}$ Surfaces}

Adsorption is an important stage in catalytic and photocatalytic reactions, as well as in the operation of sensors. Important fundamental information about the adsorption complexes can be obtained experimentally, as well as by using quantum computations. Adsorption of organic compounds can modify the band structure of $\mathrm{TiO}_{2}$ and induce visible-light adsorption. For example, a recent study by Barbierikova et al. [52] utilizing a small $\left(\mathrm{TiO}_{2}\right)_{8}\left(\mathrm{H}_{2} \mathrm{O}\right)$ cluster showed that adsorption of 4-chlorophenol on $\mathrm{TiO}_{2} \mathrm{P} 25$ resulted in the formation of surface charge transfer complexes.

Currently, the majority of computational studies, including those on adsorption processes, utilize DFT functionals. However, semiempirical methods can also be used facilitating to work with much larger systems. A recent comparison of various DFT functionals, $(\operatorname{CCSD}(\mathrm{T})$, and the semiempirical methods PM6 and PM7), used to study adsorption of diethyl sulfide and thiophene over small $\mathrm{TiO}_{2}$ clusters, showed that semiempirical methods provide correct but incomplete information, and the best method was found to be PBE0/6-31G(d) [53].

Geldof et al. studied the interaction of methylphosphonic acid with (101) and (001) surfaces of anatase [54]. This compound is of interest since it is one of the products of photocatalytic destruction 
of organophosphorus toxic compounds. Adsorption can take place in mono- and bidentate forms over (101) surface and mono-, bi-, and tridentate forms over the (001) surface of anatase. The energy of adsorption over the (001) surface $(-280 \mathrm{~kJ} / \mathrm{mol}$ and $-260 \mathrm{~kJ} / \mathrm{mol}$ for bidentate and tridentate, respectively) was found to be much larger than for the (101) surface $(-184 \mathrm{~kJ} / \mathrm{mol}$ and $-191 \mathrm{~kJ} / \mathrm{mol}$ for monodentate and bidentate, respectively).

Quintero and Nagarajan [55] investigated the adsorption of the organophosphorus molecules dimethyl methylphosphonate (DMMP), sarin, and soman over rutile (110) surface in its clean, hydroxylated and hydrated forms, using a PBE functional. Figure 6 demonstrates the major findings of their study. In agreement with the results obtained for anatase surfaces [56], dissociative adsorption over clean rutile surface is thermodynamically unfavored. However, dissociative adsorption with cleavage of $\mathrm{P}-\mathrm{O}$ bond over hydroxylated and hydrated surface is exothermic and does result in removal of the acute toxicity and volatility of such compounds.

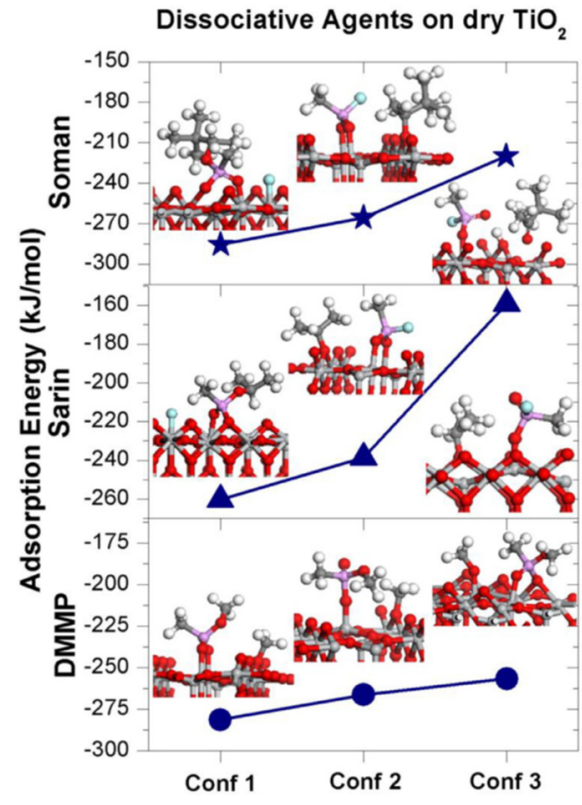

(a)

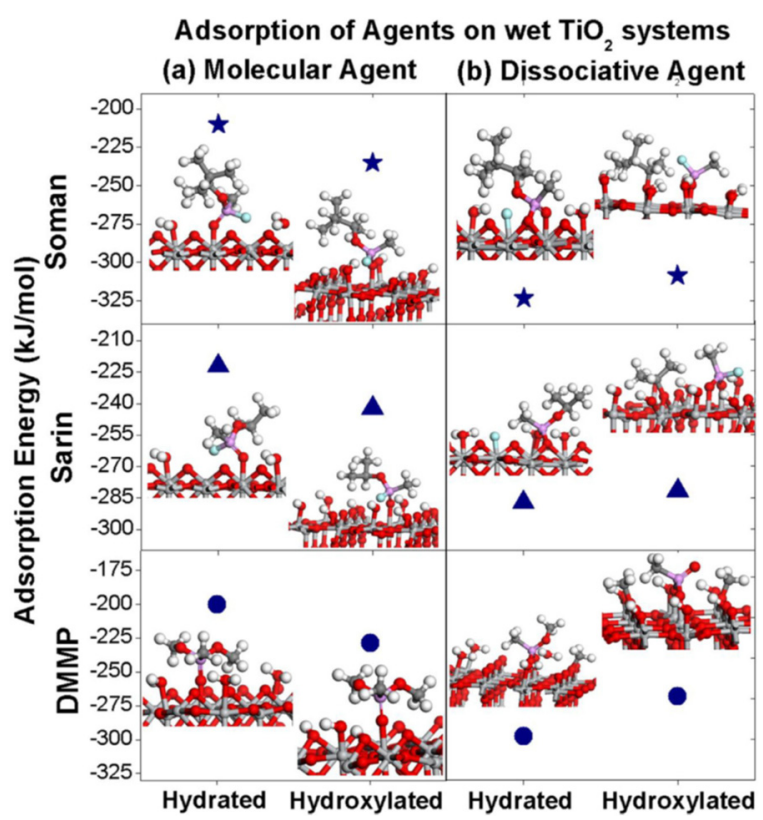

(b)

Figure 6. Molecular and dissociative adsorption of dimethyl methylphosphonate (DMMP), sarin, and soman over (a) clean rutile $\mathrm{TiO}_{2}$ (110) surface and (b) hydroxylated and hydrated rutile (110) surface. Reproduced from Reference [55] with permission; copyright (2018) Elsevier.

Rudshteyn et al. [57] considered adsorption of benzohydroxamic acid $\left(\mathrm{C}_{6} \mathrm{H}_{5} \mathrm{C}(\mathrm{O}) \mathrm{NCH}_{3}(\mathrm{OH})\right)$ over the (101) facet of anatase using DFT computations with a PBE GGA functional. The strongest adsorption was detected for monodentate binding, in which a dissociated $\mathrm{OH}$ group was connected to the surface Ti atom with adsorption energy of $-53.5 \mathrm{~kJ} / \mathrm{mol}$. The highest occupied molecular orbital (HOMO) level in this adsorption complex was located in the organic adsorbate and, hence, the light absorption threshold was somewhat shifted to the visible-light region in comparison with $\mathrm{TiO}_{2}$.

Setvin et al. [58] studied the adsorption of formaldehyde over a (101) surface of anatase using experimental and computational methods. Adsorption proceeds via the binding of the oxygen atom in formaldehyde to surface $\mathrm{Ti}_{5 \mathrm{C}}$, and its energy was found to be $-67 \mathrm{~kJ} / \mathrm{mol}$ for the most stable configuration. Scanning tunneling microscopy (STM) was used for deducing the adsorption configurations experimentally. However, this value should be taken with some precaution since determining the positions of all atoms in adsorbed small molecules (such as $\mathrm{HCHO}$ ) can be quite difficult.

A comprehensive study on the adsorption of acetone over adsorption sites on anatase nanoparticles with (001) and (010) exposed facets and on decahedral anatase nanoparticles with exposed (001) and (101) facets was undertaken recently [59]. The modern and precise semiempirical method DFTB, based 
on DFT, was utilized to obtain the structure and energy of adsorption complexes. It was found that the adsorption energy over the (001) facet increased when the size of cubic anatase nanoparticles increased. A higher adsorption energy was found for the (101) facet compared to the (001) facet in the decahedral anatase nanoparticles. Interestingly, the adsorption energy also increased considerably when the (001) surface was hydroxylated by dissociative adsorption of water molecules. It was also discovered that, for the cubic nanoparticles, photogenerated holes were mainly localized over (001) surfaces, and electrons localized over (100) surfaces and in the bulk. For some of the adsorption complexes the electrons were localized over adsorbed acetone, while, for many others, they were not. The infrared (IR) spectra of the adsorption complexes were also studied. The DFTB method produced a very good agreement with the measured band gap and with the measured $C=O$ IR peak (a theoretical value of $1784 \mathrm{~cm}^{-1}$ versus experimental value of $1735 \mathrm{~cm}^{-1}$ ). Adsorption of acetone resulted in spectral shift in the $\mathrm{C}=\mathrm{O}$ peak from $1741 \mathrm{~cm}^{-1}$ to $2027 \mathrm{~cm}^{-1}$, i.e., both a downward and an upward shift were observed as a result of acetone adsorption. The shift was claimed to be related both to a strength change in the $\mathrm{C}=\mathrm{O}$ bond and to a change in the reduced mass of the oscillator in different geometries of the adsorption complex.

Adsorption of $\mathrm{NO}$ and $\mathrm{O}_{2}$ over a clean and hydrogenated (101) anatase surface was studied theoretically by Li et al. [60]. For the clean (101) surface, $\Delta E_{\text {ads }}$ was $-47 \mathrm{~kJ} / \mathrm{mol}$ and $-19 \mathrm{~kJ} / \mathrm{mol}$ for $\mathrm{NO}$ and $\mathrm{O}_{2}$, respectively. Following hydrogenation, the adsorption was significantly stronger.

Oxygen vacancies play an important role in the processes of adsorption over $\mathrm{TiO}_{2}$ surfaces, as was revealed in a recent study by Lang et al. [61]. While methanol tends to adsorb in a molecular form over intact (101) anatase surface, it adsorbs dissociatively and much more exothermically over oxygen vacancies. Adsorption was also found to stimulate migration of oxygen vacancies to subsurface atomic layers.

Nadeem et al. [62] reported that oxygen vacancies in the anatase (101) surface serve as sites for water dissociative adsorption. Here, the room-temperature formation of two hydroxyl groups over oxygen vacancies was confirmed by a theoretical study, as well as by STM.

Adsorption of heavy metals and other water contaminants is an important process for environment protection. Chen at al. [63] reported that adsorption of aqueous U(VI) at pH 5 was stronger over (001) facets compared to (100) facets and was the weakest for the (101) facets of anatase nanoparticles. Under UV irradiation, reduction of U(VI) into surface-bound compounds was observed. Adsorption of $\mathrm{Pb}$ (II) over a (101) surface of anatase was studied computationally by Zhang et al. [64]. The computed adsorption energy was $-215 \mathrm{~kJ} / \mathrm{mol}$, which is very large, possibly due to the absence of any solvent in the computational model. Liao et al. [65] studied adsorption of $\mathrm{Pb}(\mathrm{II})$ and $\mathrm{Cd}(\mathrm{II})$ over (001) and (101) facets of anatase using experimental and computational DFT methods (PBE GGA functional). They found a higher adsorption energy of these cations upon adsorption on the (001) surface: $-250 \mathrm{~kJ} / \mathrm{mol}$ vs. $-227 \mathrm{~kJ} / \mathrm{mol}$ for $\mathrm{Pb}(\mathrm{II})$ and -46 vs. $-13 \mathrm{~kJ} / \mathrm{mol}$ for $\mathrm{Cd}(\mathrm{II})$. This theoretical result was confirmed by experimental results showing higher tendency for adsorption of metallic cations on nanoparticles having dominant (001) facets in comparison with nanoparticles having a high number of (101) surfaces.

Adsorption of dyes onto the surface of $\mathrm{TiO}_{2}$ is a crucial stage in the fabrication of dye sensitized solar cells (DSSC). Gao et al. [66] recently studied the binding of retinoic acid to $\mathrm{TiO}_{2}$ experimentally and computationally. They identified three anchoring modes via which the carboxyl group is attached to the $\mathrm{TiO}_{2}$ surface: bidentate binding to two surface Ti cations, bidentate binding to Ti and to surface $\mathrm{O}$, and bidentate binding to surface $\mathrm{Ti}$ and to a surface $\mathrm{OH}$ group. Analogously to many similar studies, a very small and amorphous $\left(\mathrm{TiO}_{2}\right)_{16}$ cluster was used for the theoretical study, which undermines the accuracy of extrapolation of the electronic properties to real $\mathrm{TiO}_{2}$ nanoparticles.

An interesting application of anatase $\mathrm{TiO}_{2}$ films is in the fabrication of resistive gas sensors. Liang et al. [67] prepared two anatase samples: one containing predominantly (010) facets and a second containing predominantly (101) facets. It turned out (see Figure 7) that the drop in resistance upon exposure to acetone vapors was approximately twice as large for the sample containing (010) facets, 
an indication of more efficient charge injection into the (010) $\mathrm{TiO}_{2}$ surface upon oxidation at the sensor working temperature $\left(320^{\circ} \mathrm{C}\right)$.
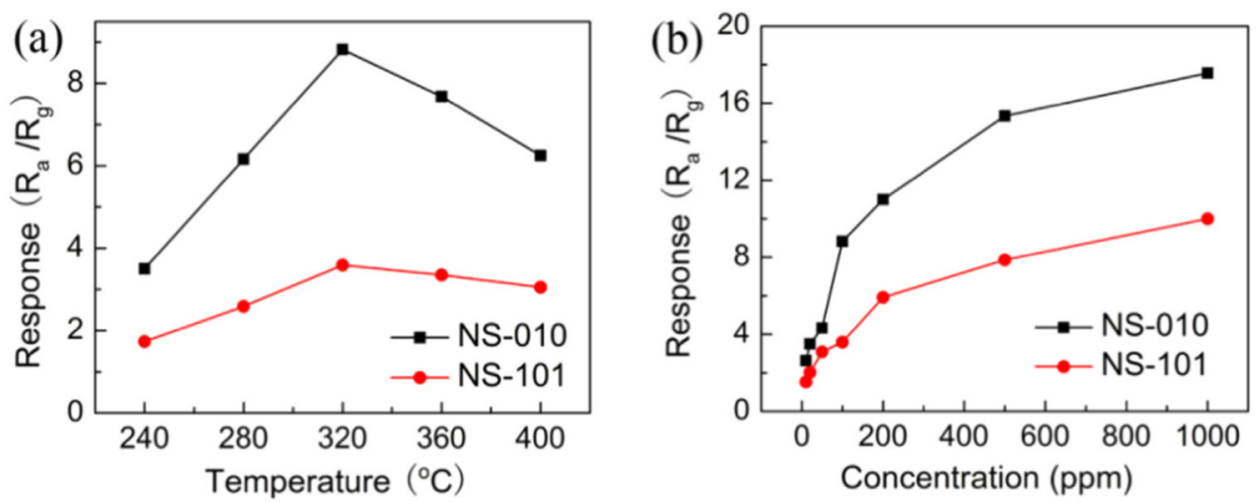

Figure 7. Resistive sensor response for anatase films containing crystallites with (010) and (101) surfaces (a) at $100 \mathrm{ppm}$ acetone concentration and different sensor temperature, and (b) at $320^{\circ} \mathrm{C}$ and different acetone concentration. Reproduced from Reference [67] with permission; copyright (2018) Elsevier.

\section{Doping of $\mathrm{TiO}_{2}$ and Its Effect on Adsorption}

The introduction of dopants into the $\mathrm{TiO}_{2}$ lattice and on the surface can dramatically change the properties of the photocatalyst [68]. A wide variety of elements are used as dopants for titanium dioxide, including N, Sn, V, and Pt. Some of these dopants induced visible-light photocatalytic activity. Nitrogen doping via substitution of oxygen atoms seems to be the most widely studied [69]. It leads to intraband states close to the valence band and stabilization of oxygen vacancies. The basic nature of $\mathrm{Mg}^{2+}$ cations makes adsorption of acidic molecules like $\mathrm{CO}_{2}$ much stronger, and this can improve the efficiency of photoreactions. $\mathrm{Mg}$ atoms can also serve as sites for reactive adsorption. Sasani et al. [70] studied, with a PBE functional, the $\mathrm{Mg}$ doping in the (101) facet represented by a $\mathrm{Ti}_{32} \mathrm{O}_{64}$ slab. They found that surface $\mathrm{Ti}_{5 \mathrm{C}}$ sites are more stable after substitution with $\mathrm{Mg}^{2+}$ compared to $\mathrm{Ti}_{6 \mathrm{C}}$ sites. $\mathrm{Mg}^{2+}$ sites tend to be placed as far as possible from each other.

Hiremath et al. [71] synthesized $\mathrm{MgO}-\mathrm{TiO}_{2}$ composites with different ratios of $\mathrm{Mg}$ to $\mathrm{Ti}$ in the range of $0-5$. Formation of different phases such as $\mathrm{MgTiO}_{3}, \mathrm{MgO}-\mathrm{MgTi}_{2} \mathrm{O}_{4}$, and $\mathrm{MgO}-\mathrm{Mg}_{2} \mathrm{TiO}_{4}$ was detected. The best phase for $\mathrm{CO}_{2}$ adsorption was found to be $\mathrm{MgTiO}_{3}$.

Shakir at al. [72] prepared Mg-doped $\mathrm{TiO}_{2}$ films and applied them for constructing DSSCs. They discovered that $\mathrm{Mg}$ doping induced visible-light absorption via introduction of intraband energy levels. DSSCs utilizing doped $\mathrm{TiO}_{2}$ demonstrated improved efficiency compared to DSSCs utilizing undoped $\mathrm{TiO}_{2}$.

$\mathrm{Mg}$ doping for anatase $\mathrm{TiO}_{2}$ was demonstrated beneficial for the photocatalytic reduction of $\mathrm{CO}_{2}$ into $\mathrm{CO}, \mathrm{CH}_{3} \mathrm{OH}$, and $\mathrm{CH}_{4}$ [73]. The mechanism of the $\mathrm{Mg}$ effect was investigated computationally. It turned out that $\mathrm{Mg}$ surface sites were accompanied by oxygen vacancies that served as sites for strong $\mathrm{CO}_{2}$ adsorption ( $\Delta \mathrm{H}_{\mathrm{ads}}$ up to $-163 \mathrm{~kJ} / \mathrm{mol}$ compared to about $-21 \mathrm{~kJ} / \mathrm{mol}$ for pristine $\mathrm{TiO}_{2}$ ). This study hints at the design of most active photocatalysts at atomic precision since only a few specific doping sites possessed very high adsorption enthalpy for $\mathrm{CO}_{2}$.

Sulfur is a prominent and widely occurring dopant in $\mathrm{TiO}_{2}$. It is inherently present as a result of utilization of sulfur-containing precursors in the preparation of titanium. It may exist at the surface and in inner layers of $\mathrm{TiO}_{2}$ particles, either in an anionic form $\left(\mathrm{S}^{2-}\right)$ or in a cationic form $\left(\mathrm{S}^{4+}\right.$ and $S^{6+}$ ). The simplest method of preparing cationically S-doped $\mathrm{TiO}_{2}$ consists of calcination of $\mathrm{TiOSO}_{4}$ at a temperature of $700{ }^{\circ} \mathrm{C}$ or lower [74]. Doping with sulfur was demonstrated to have a positive influence on the stability during calcination, on porosity, on nanoparticle size, and on the visible-light photocatalytic activity of anatase $\mathrm{TiO}_{2}$ [75].

Due to the positive effects of sulfur doping, S-doped anatase was a subject of intensive experimental and theoretical research. Cationic doping of anatase with sulfur proceeds via substitution of lattice 
titanium atoms with sulfur atoms. Such a substitution can result in narrowing of the material band gap since S(IV) orbitals contribute to the valence band [76]. In a recent study [77], a close-to-reality model of S-doped $\mathrm{TiO}_{2}$ was suggested in which the anatase was represented by a cluster having a highly hydroxylated surface. This model is reminiscent of the real anatase materials prepared from titanyl sulfate and containing residual sulfuric acid or multiple sulfate groups in its surface layers. Using a theoretical DFTB method, it was demonstrated that, after cationic substitution in $\mathrm{TiO}_{2}$, sulfur retains its geometry characteristic for sulfates (for S(VI)) or sulfites (for S(IV)). All possible locations of sulfur in the decahedral anatase cluster were evaluated. It turned out that surface doping was preferable compared to bulk doping. Doping with S(VI) resulted only in a very small decrease in the band gap, from $3.22 \mathrm{eV}$ to $2.96 \mathrm{eV}$, while $\mathrm{S}(\mathrm{IV})$ doping resulted in visible-light absorption with $\mathrm{E}_{\mathrm{g}}=2.65 \mathrm{eV}$.

\section{Dark Reactions over $\mathrm{TiO}_{2}$ Surfaces}

The adsorption of reagents is the first stage in the majority of catalytic reactions. This is also true for photocatalytic transformations. The surface of $\mathrm{TiO}_{2}$ under atmospheric conditions contains undercoordinated $\mathrm{Ti}^{4+}$, hydroxyl groups, adsorbed water, and other species. Therefore, adsorption over $\mathrm{TiO}_{2}$ can result in retaining the molecular structure of the adsorbate or its partial destruction as a consequence of surface reactions, i.e., adsorption can be molecular or reactive.

Air purification from toxic compounds that might be present in low concentrations is one of the most important applications of photocatalytic oxidation. It is desirable that the toxic pollutants become much less toxic right after their adsorption, i.e., already before the photoreaction. This is attained for a number of air pollutants including chemical warfare agents (CWAs) and their non-toxic simulants.

The possibility of reactive adsorption was recently studied for the malodorous compound and CWA stimulant diethyl sulfide (DES) using quantum computations [78]. A 2-nm anatase $\mathrm{TiO}_{2}$ nanoparticle, exposing (001), (100), and (010) facets, was taken. All possible adsorption sites were considered. It was found that molecular adsorption proceeded via coordinating the sulfur atom of DES to surface oxygen atoms. The adsorption enthalpy varied in the range of $-25 \mathrm{~kJ} / \mathrm{mol}$ to $-159 \mathrm{~kJ} / \mathrm{mol}$. Dissociative adsorption was found exothermic only for (100) surface and resulted in - $\mathrm{SCH}_{2} \mathrm{CH}_{3}$ and $-\mathrm{CH}_{2} \mathrm{CH}_{3}$ fragments adsorbed to Ti and $\mathrm{O}$ atoms. Thus, anatase $\mathrm{TiO}_{2}$ with a large fraction of reactive (100) surface seems to be beneficial for air purification devices.

For photoelectrochemical processes, of importance are the electron transfer reactions at the photoelectrode-electrolyte interface. Zhou et al. [79] prepared $\mathrm{TiO}_{2}$ specimens containing predominantly (001) surfaces and calcined them at different temperatures. Increasing concentrations of oxygen vacancies upon elevating the calcination temperature were registered using Raman spectroscopy. A concept of a reductive interaction of oxygen vacancies with $\mathrm{O}_{2}$ to form $\mathrm{O}_{2}{ }^{-}$was suggested to explain the higher current density for reactions of $\mathrm{Hg}(\mathrm{II})$ at the electrode. However, the detection of $\mathrm{V}_{\mathrm{O}}$ defects was not conclusive since their concentration was very low.

\section{Surface Structure Effects in Photoreactions over $\mathrm{TiO}_{2}$}

\subsection{Clean Anatase $\mathrm{TiO}_{2}$}

The ridge atoms over the $(1 \times 4)$ reconstructed anatase $(001)$ surface were recently demonstrated to play a decisive role in methanol photooxidation over a single crystal sample [80]. These ridges contain $\mathrm{Ti}_{4 \mathrm{C}}$ atoms, in contrast to $\mathrm{Ti}_{5 \mathrm{C}}$ atoms over the intact (001) surface. Such coordinatively unsaturated $\mathrm{Ti}$ sites were suggested to be the active sites for methanol photooxidation.

Anatase crystallites typically have exposed (101) and (001) surfaces. With proper preparation methods, some other facets can be obtained. The presence of a larger fraction of (001) facets is generally reported to result in a higher photocatalytic activity [81]. The preparation typically utilizes HF to decrease the surface energy of the (001) facet due to the strong Ti-F interaction. Therefore, the increased activity of anatase catalysts with a large fraction of the (001) facet is attributed to the presence of fluoride anions over this surface. Indeed, Lei and Lu showed that decahedral anatase nanoparticles 
washed with $\mathrm{NaOH}$ to remove the surface fluoride anions possessed higher photoactivity of (101) facets compared to (001) facets [82]. However, the question remains how the presence of fluoride anions can improve photocatalytic activity. Chen et al. suggested that adsorbed $\mathrm{F}^{-}$ions formed a electrostatic field that attracted photogenerated holes to the (001) surface [83]. This explained the higher activity in the photooxidation of $\mathrm{NH}_{3}$ on anatase containing $95 \%$ (001) surfaces in comparison with samples that did not contain $\mathrm{F}^{-}$and surfaces with lower fraction of (001), as well as with fluorinated (101) facets. The (001) surface also demonstrated a higher efficiency in a DSSC solar cell, sensitized with N719 dye compared to the (100) surface [84].

Unfortunately, a discrepancy between experimental data and theory with respect to the localization of photogenerated electrons and holes still exists. Experimental data on photodeposition of $\mathrm{Pt}$ and $\mathrm{PbO}_{2}$ revealed localization of electrons over the (101) surface and holes over the (001) surface. Theoretical calculations usually predict localization of both charge carriers in (101) facets. The computational results of Ma et al. [85] also confirmed the higher photocatalytic activity in $\mathrm{CO}_{2}$ photoreduction of (101) facets of anatase compared to (001) facets due to more favorable energy levels of electrons in the (101) facet. No fluoride anions were added to the (001) facet in their study.

Setvin et al. [86] carried out a study on methanol photoactivation over (101) surface of anatase, using STM, TPD, XPS, and DFT. They found that dissociative adsorption of $\mathrm{CH}_{3} \mathrm{OH}$ with the formation of surface bound methoxy groups was a prerequisite for further photocatalytic oxidation reaction. The DFT calculation, done using a PBE GGA functional and Hubbard repulsion correction with $U_{\text {eff }}=+3.9 \mathrm{eV}$ for the Ti $3 \mathrm{~d}$ orbitals, revealed that dissociative adsorption was energetically unfavorable. If it proceeds near a surface $\mathrm{OH}$ group, the dissociation becomes allowed and results in the formation of $\mathrm{H}_{2} \mathrm{O}$ that desorbs from the surface. Experimental data also showed dissociative adsorption and formation of $\mathrm{HCHO}$ under UV irradiation at low surface coverages. At high coverages, above 0.5 monolayer (ML), methyl formate was the photoreaction product. The DFT computation of the phototransformation of $\mathrm{CH}_{3} \mathrm{O}$ into $\mathrm{HCHO}$ found only a small energy barrier of $0.2 \mathrm{eV}$.

\subsection{Oxygen Vacancies}

Introduction of a high concentration of intrinsic defects into the $\mathrm{TiO}_{2}$ surface is a method for improvement of photocatalytic activity together with sensitivity toward visible light. Substoichiometric titanium dioxide $\left(\mathrm{TiO}_{2-\mathrm{x}}\right)$ can be obtained, for example, via reduction of $\mathrm{TiO}_{2}$ or via calcination of metatitanic acid. Introduction of $\mathrm{V}_{\mathrm{O}}$ in the bulk and in the surface of $\mathrm{TiO}_{2}$ resulted in strong improvements of $\mathrm{CO}_{2}$ photoreduction into $\mathrm{CH}_{4}$ under $\mathrm{UV}$ or visible light [87].

$\mathrm{V}_{\mathrm{O}}$ is an inherent component of $\mathrm{TiO}_{2}$ material since titanium dioxide is known to be an n-type semiconductor and almost always has a deficit of oxygen in its structure. It turned out that surface oxygen vacancies have an important role in photocatalytic reactions. In particular, reduction of $\mathrm{CO}_{2}$ proceeds in the adsorbed state at surface oxygen vacancies $\mathrm{V}_{\mathrm{O}}$. Ji and Luo investigated such a reduction into $\mathrm{CO}$ and $\mathrm{CH}_{4}$ over $\mathrm{V}_{\mathrm{O}}$ in the (101) facet [88]. It was found that $\mathrm{V}_{\mathrm{O}}$ considerably reduces the reaction barrier compared to adsorption and reaction over surface Ti atoms. Oxygen vacancies play a key role in the reaction of dark and photocatalytic decomposition of $\mathrm{N}_{2} \mathrm{O}$ over anatase (001) and (101) surfaces [89]. Figure 8 demonstrates that such reactions lead to filling the vacancy and, thus, its regeneration is an obligatory stage for the good and lasting photocatalytic activity. Moreover, photocatalytic hydrogen generation from water is possible over surface-reduced $\mathrm{TiO}_{2}$ without the addition of co-catalysts [90].

In line with these observations are the recent studies on photocatalytic reactions employing reduced $\mathrm{TiO}_{2}$. One of the methods to produce partially reduced $\mathrm{TiO}_{2}$ consists of calcination at $200-400{ }^{\circ} \mathrm{C}$ in vacuum [90]. An observed gray coloration indicated partial reduction of $\mathrm{TiO}_{2}$. Visible-light photocatalytic activity in the degradation of tetracycline and RhB increased significantly when the vacuum calcination temperature was increased to $300^{\circ} \mathrm{C}$. However, Hou et al. [91] suggested from their studies on photocatalytic hydrogen production that only surface oxygen vacancies have a positive effect on separation of electron-hole pairs while single-electron-trapped oxygen vacancies (SETOV) in the bulk induce recombination of charge carriers. Surface oxygen vacancies were suggested to be 
produced in vacuum calcination, while calcination of nanotubes in air produced SETOV according to ESR data. This result is in agreement with enhanced photocurrent and photocatalytic activity in $\mathrm{H}_{2}$ generation observed with anatase $\mathrm{TiO}_{2}$ that was reduced by ethylene glycol at $180{ }^{\circ} \mathrm{C}$ [92].

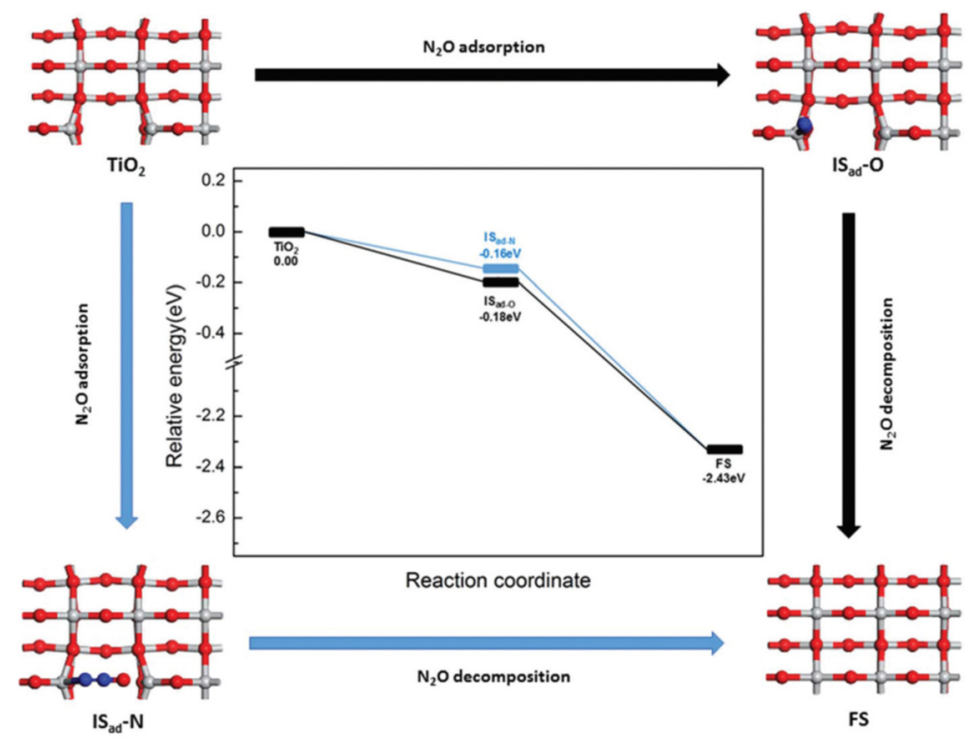

Figure 8. Decomposition of $\mathrm{N}_{2} \mathrm{O}$ over an anatase (001) surface containing an oxygen vacancy. Reproduced with permission from Reference [89]; copyright (2018) The Royal Society of Chemistry.

Various co-catalysts can be used in order to improve the photocatalytic activity of $\mathrm{TiO}_{2}$, and this is one of the most often used approaches. Graphene was a very popular object of research in recent years, and its combination with $\mathrm{TiO}_{2}$ and $\mathrm{Pt}$ nanoparticles was found to be beneficial for reactions of photocatalytic oxidation of volatile organic compounds (VOCs) [93]. In graphene-containing heterojunctions, graphene can act as electron conductor to the active sites in another co-catalyst or can serve as a reduction or oxidation electrocatalyst [94]. Questions arise as to the nature of interactions between graphene (GR), graphene oxide (GO), and $\mathrm{TiO}_{2}$ and the causes for the improved photocatalytic properties of $\mathrm{TiO}_{2} / \mathrm{GR}$ or $\mathrm{TiO}_{2} / \mathrm{GO}$ composites. Figure 9 shows the structure of anatase-GR and anatase-GO interfaces. Experimentally, it was found that GR and GO loading can decrease the anatase band gap [95]. This decrease can be related to the formation of additional states associated with the interaction of $\mathrm{TiO}_{2}$ and graphene.

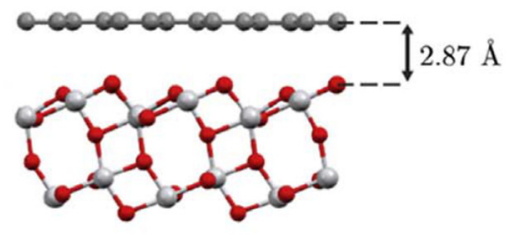

(a)

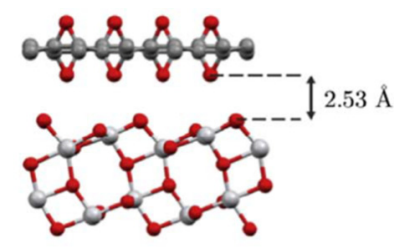

(b)

Figure 9. Interaction with the (101) surface of anatase of graphene (a) and graphene oxide (b). Reproduced with permission from Reference [95]; copyright (2018) Elsevier.

Indeed, analysis of orbitals and their energies in a cluster model involving a decahedral anatase nanoparticle and a fragment of graphene sheet showed that their interaction resulted in additional intraband states, and these states could participate in the photoexcitation of the composite under visible light [96]. Such new states caused visible-light-stimulated methanol production from $\mathrm{CO}_{2}$ at a rate comparable to that under UV irradiation. The study of Piskorz et al. [97] performed by DFT and 
TD DFTB also points to the electronic coupling between $\mathrm{TiO}_{2}$ clusters and reduced graphene oxide (RGO) sheets, resulting in the photogeneration of electrons in the RGO.

The photocatalytic activity of decahedral anatase nanoparticles could be further improved by loading a $\mathrm{Co}_{3} \mathrm{O}_{4}$ oxidation co-catalyst on an F-doped (001) facet and a Pt reduction co-catalyst on (101) facets [98]. A decrease in ineffective reaction barriers was obviously the cause for the almost 10-fold increase in $\mathrm{H}_{2}$ photocatalytic production rate on $\mathrm{Pt} / \mathrm{TiO}_{2} / \mathrm{Co}_{3} \mathrm{O}_{4}$ compared to hydrogen production with $\mathrm{TiO}_{2} / \mathrm{Co}_{3} \mathrm{O}_{4}$.

\section{Transient Phenomena in $\mathrm{TiO}_{2}$ as a Tool for Understanding Its Photocatalytic Properties}

From the early days of photocatalysis, it was understood that studying the whereabouts of photoinduced charge carriers could be the key for understanding the photocatalytic properties of titanium dioxide. Measuring transient phenomena following excitation may provide the essential knowledge required for designing efficient photoactive materials, especially if combined with appropriate theory. Accordingly, most of the manuscripts reporting on transient phenomena in $\mathrm{TiO}_{2}$ were published prior to this decade, but they are still relevant. For example, electron paramagnetic resonance (EPR) spectroscopy provided valuable information on the trapping of photogenerated electrons within the bandgap of $\mathrm{TiO}_{2}$, suggesting localization on $\mathrm{Ti}^{3+}$ centers [99], while time-resolved photocharge (TRPC) measurements yielded the lifetime of the charge carriers [100]. Another technique for measuring transient phenomena is time-resolved microwave conductivity (TRMC), based on measuring changes in microwave power reflected from samples following photoexcitation, thus providing values for the lifetimes of photoexcited electrons in different types of $\mathrm{TiO}_{2}$ of different phases, particle sizes, and modifications [101].

A common technique to study the dynamics of photoactive materials is UV-Vis absorption/ reflection. Based on this technique, evidence was found that the photogenerated electrons tend to be trapped at $\mathrm{Ti}^{4+}$ centers, forming $\mathrm{Ti}^{3+}$, the lifetime of which was determined by following the recombination with the holes and by the interfacial transfer to molecules adsorbed at the surface. Of large importance are studies of sub-nanosecond relaxation dynamics in colloidal sols of titanium dioxide, where transient absorption spectra in the visible region yielded important information on the dependence of electron localization $\left(\mathrm{Ti}^{3+}\right)$ and surface trapped holes on the particles' size [102]. The same technique was used to locate two different types of hole traps in $\mathrm{TiO}_{2}$ : deep traps containing unreactive holes that exhibit absorption at $450 \mathrm{~nm}$, and shallow traps containing active holes having very high oxidation potential [103]. In a similar manner, spectral resolution enabled following trapped states on the surface of $\mathrm{TiO}_{2}$ by taking advantage of the fact that the absorption peaks of free $\mathrm{OH}$ and free $\mathrm{O}^{2-}$ are around $260 \mathrm{~nm}$ [104]. A recent review, summarizing transient UV absorption measurements on the trapping dynamics of photogenerated electrons and holes in titanium dioxide, presented a large diversity in the measured decaying timescales, as $t_{1 / 2}$ ranged from 50 fs to $50 \mathrm{ps}$ for trapping, 1 ps to more than $20 \mathrm{~ns}$ for recombination, and $300 \mathrm{ps}$ to $0.1 \mathrm{~ms}$ for interfacial charge transfer [105]. In general, a correlation was found between longer decay times of $\Delta$ abs in transient UV absorption/reflection measurements and higher activities. For example, time-resolved emission quenching studies comparing different forms of titanium dioxide found an average decay constant of $1.99 \mathrm{~ns}$ for anatase and $1.65 \mathrm{~ns}$ for the less active rutile phase [106]. Likewise, it was found that decorating titanium dioxide with Pt islands, acting as electron sinks, extended the life time of trapped holes from the picosecond to the millisecond time scale, in correlation with the observation of higher activity [107].

The presence of trapped charges, whether at the bulk or at the surface of a photocatalyst, affects the potential that the neighboring atoms experience. As a consequence, it is reasonable to assume that the trapped charges are likely to affect the localized modes of vibration of the atoms in the vicinity of the trapped charge. The effects may include a change in the location of the vibrational levels in the energy scale and a change in the derivative of the dipole moment with respect to displacement [101]. The former is expected to be manifested by a shift in the frequencies of specific IR/Raman peaks, whereas the 
latter may be manifested by changes in the intensity of specific peaks, since the (frequency-dependent) extinction coefficient depends on the transition moment, which is strongly affected by the derivative of the dipole moment. In addition to that, a positive drift of the whole spectrum (i.e., regardless of wavenumber) may indicate that absorption of the IR photons excites charge carriers into a continuous band rather than to discrete levels. Transient changes in the IR spectrum of titanium dioxide were measured using a dispersive approach, following excitation by a laser pulse at $355 \mathrm{~nm}$. A fast increase (faster than $50 \mathrm{~ns}$ ) in the absorption of the whole IR spectrum $\left(1000-4000 \mathrm{~cm}^{-1}\right)$, followed by a gradual decay back to the pre-excitation spectrum within $100 \mathrm{~ms}$, was observed by Yamakata, Ishibashi, and Onishi [108]. The observation that the increase in the IR absorption was non-specific indicated that the transition of photogenerated electrons into the conduction band was either in an intra-band manner or from shallow midgap trap states. By monitoring the effect of electron scavengers and hole scavengers, it was concluded that trapped holes and electrons were localized on the surface of the photocatalyst, whereas free electrons were distributed in the bulk. A considerable body of research was performed on $\mathrm{Pt} / \mathrm{TiO}_{2}$, both under vacuum and in the presence of water vapor [109]. Development of means for measuring transient changes in the IR spectrum at the sub-nanosecond time domain enabled differentiating between trapping at shallow traps (typical time $=15 \mathrm{ps}$ ) and trapping at unreactive deeper traps (typical time $=150 \mathrm{ps}$ ) in $\mathrm{TiO}_{2}$ aerogels [110]. Quite counter-intuitively, no correlation was found between the number of electron trapping sites and the decay rate to the deeper traps. Moreover, the quantitative relationship between the activity (as probed by the photocatalytic degradation rate of dichloroacetate) and the transient behavior at the sub-nanosecond timescale was reported to be unclear.

\section{Conclusions}

It can be concluded that investigations on surfaces of clean, doped, and impregnated titanium dioxide comprise a vigorously developing research field. Theoretical computational methods deliver surface and nanoparticle structure designs that correspond to improved photocatalysts. Moreover, many findings in the field of photocatalysis can be used for the preparation of very active thermally activated catalysts. This is especially true for the effects of surface structure and dopants on properties of individual surface sites.

Author Contributions: Conceptualization, A.V.V. and Y.P.; writing—original draft preparation, A.V.V.; writing—review and editing, A.V.V., P.G.S., Y.P.; supervision, Y.P.; project administration, Y.P.; funding acquisition, Y.P., H.V., P.G.S. All authors have read and agreed to the published version of the manuscript.

Funding: This research was funded by the European Commission, grant No. AMD-776816-6.

Conflicts of Interest: The authors declare no conflicts of interest.

\section{References}

1. Liu, C.; Lu, H.; Zhang, J.; Yang, Z.; Zhu, G.; Yin, F.; Gao, J.; Chen, C.; Xin, X. Abnormal p-type sensing response of $\mathrm{TiO}_{2}$ nanosheets with exposed \{001\} facets. J. Alloys Compd. 2017, 705, 112-117. [CrossRef]

2. Pližingrová, E.; Klementová, M.; Bezdička, P.; Boháček, J.; Barbieriková, Z.; Dvoranová, D.; Mazúr, M.; Krýsa, J.; Šubrt, J.; Brezová, V. 2D-Titanium dioxide nanosheets modified with Nd, Ag and Au: Preparation, characterization and photocatalytic activity. Catal. Today 2017, 281, 165-180. [CrossRef]

3. Scanlon, D.O.; Dunnill, C.W.; Buckeridge, J.; Shevlin, S.A.; Logsdail, A.J.; Woodley, S.M.; Catlow, C.R.A.; Powell, M.J.; Palgrave, R.G.; Parkin, I.P.; et al. Band alignment of rutile and anatase $\mathrm{TiO}_{2}$. Nat. Mater. 2013, 12, 798-801. [CrossRef] [PubMed]

4. Besov, A.S.; Vorontsov, A.V. Fast elimination of organic airborne compounds by adsorption and catalytic oxidation over aerosol $\mathrm{TiO}_{2}$. Catal. Commun. 2008, 9, 2598-2600. [CrossRef]

5. Tsydenov, D.E.; Shutilov, A.A.; Zenkovets, G.A.; Vorontsov, A.V. Hydrous $\mathrm{TiO}_{2}$ materials and their application for sorption of inorganic ions. Chem. Eng. J. 2014, 251, 131-137. [CrossRef] 
6. Li, C.; Koenigsmann, C.; Ding, W.; Rudshteyn, B.; Yang, K.R.; Regan, K.P.; Konezny, S.J.; Batista, V.S.; Brudvig, G.W.; Schmuttenmaer, C.A.; et al. Facet-Dependent Photoelectrochemical Performance of $\mathrm{TiO}_{2}$ Nanostructures: An Experimental and Computational Study. J. Am. Chem. Soc. 2015, 137, 1520-1529. [CrossRef]

7. Peng, Y.-K.; Tsang, S.C.E. Facet-dependent photocatalysis of nanosize semiconductive metal oxides and progress of their characterization. Nano Today 2018, 18, 15-34. [CrossRef]

8. Shi, Y.; Sun, H.; Saidi, W.A.; Nguyen, M.C.; Wang, C.Z.; Ho, K.; Yang, J.; Zhao, J. Role of Surface Stress on the Reactivity of Anatase $\mathrm{TiO}_{2}$ (001). J. Phys. Chem. Lett. 2017, 8, 1764-1771. [CrossRef]

9. Yin, W.-J.; Wen, B.; Zhou, C.; Selloni, A.; Liu, L.-M. Excess electrons in reduced rutile and anatase $\mathrm{TiO}_{2}$. Surf. Sci. Rep. 2018, 73, 58-82. [CrossRef]

10. Liu, B.; Zhao, X.; Yu, J.; Parkin, I.P.; Fujishima, A.; Nakata, K. Intrinsic intermediate gap states of $\mathrm{TiO}_{2}$ materials and their roles in charge carrier kinetics. J. Photochem. Photobiol. C Photochem. Rev. 2019, 39, 1-57. [CrossRef]

11. Vorontsov, A.V. Cluster models of photocatalytic anatase $\mathrm{TiO}_{2}$ nanoparticles and their computational characterization. Catal. Today 2015, 252, 168-176. [CrossRef]

12. Fazio, G.; Ferrighi, L.; Di Valentin, C. Photoexcited carriers recombination and trapping in spherical vs. faceted $\mathrm{TiO}_{2}$ nanoparticles. Nano Energy 2016, 27, 673-689. [CrossRef]

13. Vorontsov, A.V. Effect of the Structure of Small Anatase Nanoparticles on the Localization of Photogenerated Charge Carriers. Kinet. Catal. 2017, 58, 688-694. [CrossRef]

14. Vorontsov, A.V.; Tsydenov, D.E. Arrangement of acid sites on the surfaces of anatase titanium dioxide nanoparticles according to cluster models. Kinet. Catal. 2014, 55, 409-415. [CrossRef]

15. Lamiel-Garcia, O.; Ko, K.C.; Lee, J.Y.; Bromley, S.T.; Illas, F. When Anatase Nanoparticles Become Bulklike: Properties of Realistic $\mathrm{TiO}_{2}$ Nanoparticles in the 1-6 nm Size Range from All Electron Relativistic Density Functional Theory Based Calculations. J. Chem. Theory Comput. 2017, 13, 1785-1793. [CrossRef] [PubMed]

16. Selli, D.; Fazio, G.; Di Valentin, C. Modelling realistic $\mathrm{TiO}_{2}$ nanospheres: A benchmark study of SCC-DFTB against hybrid DFT. J. Chem. Phys. 2017, 147, 164701. [CrossRef]

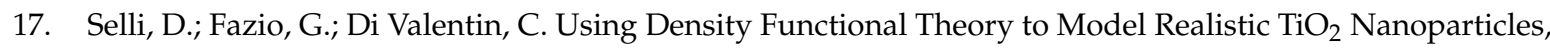
Their Photoactivation and Interaction with Water. Catalysts 2017, 7, 357. [CrossRef]

18. Valero, R.; Morales-García, Á.; Illas, F. Theoretical Modeling of Electronic Excitations of Gas-Phase and Solvated $\mathrm{TiO}_{2}$ Nanoclusters and Nanoparticles of Interest in Photocatalysis. J. Chem. Theory Comput. 2018, 14, 4391-4404. [CrossRef]

19. Vorontsov, A.V.; Smirniotis, P.G. Size and surface groups effects in decahedral anatase nanoparticles for photocatalytic applications. J. Photochem. Photobiol. Chem. 2018, 363, 51-60. [CrossRef]

20. Le, N.Q.; Schweigert, I.V. Modeling Electronic Trap States at Interfaces between Anatase Nanoparticles. J. Phys. Chem. C 2017, 121, 14254-14260. [CrossRef]

21. Vorontsov, A.V.; Smirniotis, P.G. Semiempirical computational study of oxygen vacancies in a decahedral anatase nanoparticle. Int. J. Quantum Chem. 2019, 119, e25806. [CrossRef]

22. Morales-García, Á.; Lamiel-García, O.; Valero, R.; Illas, F. Properties of Single Oxygen Vacancies on a Realistic $\left(\mathrm{TiO}_{2}\right)_{84}$ Nanoparticle: A Challenge for Density Functionals. J. Phys. Chem. C 2018, 122, 2413-2421. [CrossRef]

23. Morita, K.; Yasuoka, K. Density functional theory study of atomic and electronic properties of defects in reduced anatase $\mathrm{TiO}_{2}$ nanocrystals. AIP Adv. 2018, 8, 035119. [CrossRef]

24. Drozd, V.S.; Zybina, N.A.; Abramova, K.E.; Parfenov, M.Y.; Kumar, U.; Valdés, H.; Smirniotis, P.G.; Vorontsov, A.V. Oxygen vacancies in nano-sized $\mathrm{TiO}_{2}$ anatase nanoparticles. Solid State Ion. 2019, 339, 115009. [CrossRef]

25. Yin, G.; Huang, X.; Chen, T.; Zhao, W.; Bi, Q.; Xu, J.; Han, Y.; Huang, F. Hydrogenated Blue Titania for Efficient Solar to Chemical Conversions: Preparation, Characterization, and Reaction Mechanism of $\mathrm{CO}_{2}$ Reduction. ACS Catal. 2018, 8, 1009-1017. [CrossRef]

26. Ko, K.C.; Lee, J.Y.; Illas, F. Modeling realistic titania nanoparticles. In Frontiers of Nanoscience; Elsevier: Amsterdam, The Netherlands, 2018; Volume 12, pp. 205-238. ISBN 978-0-08-102232-0.

27. Wang, T.; Liu, L.; Ge, G.; Liu, M.; Zhou, W.; Chang, K.; Yang, F.; Wang, D.; Ye, J. Two-dimensional titanium oxide nanosheets rich in titanium vacancies as an efficient cocatalyst for photocatalytic water oxidation. J. Catal. 2018, 367, 296-305. [CrossRef]

28. Wang, Y.; Liu, J.; Wang, M.; Pei, C.; Liu, B.; Yuan, Y.; Liu, S.; Yang, H. Enhancing the Sensing Properties of $\mathrm{TiO}_{2}$ Nanosheets with Exposed $\{001\}$ Facets by a Hydrogenation and Sensing Mechanism. Inorg. Chem. 2017, 56, 1504-1510. [CrossRef] [PubMed] 
29. Liao, T.; Sun, Z.; Dou, S.X. Theoretically Manipulating Quantum Dots on Two-Dimensional TiO $\mathrm{M}_{2} \mathrm{Monolayer}$ for Effective Visible Light Absorption. ACS Appl. Mater. Interfaces 2017, 9, 8255-8262. [CrossRef] [PubMed]

30. Song, Y.; Wang, H.; Xiong, J.; Guo, B.; Liang, S.; Wu, L. Photocatalytic hydrogen evolution over monolayer H1.07Ti1.73O $\mathrm{O}_{4} \cdot \mathrm{H}_{2} \mathrm{O}$ nanosheets: Roles of metal defects and greatly enhanced performances. Appl. Catal. B Environ. 2018, 221, 473-481. [CrossRef]

31. Wang, H.; Song, Y.; Xiong, J.; Bi, J.; Li, L.; Yu, Y.; Liang, S.; Wu, L. Highly selective oxidation of furfuryl alcohol over monolayer titanate nanosheet under visible light irradiation. Appl. Catal. B Environ. 2018, 224, 394-403. [CrossRef]

32. Liu, Y.; Zhou, W.; Wu, P. The electronic structure and optical properties of donor-acceptor codoped $\mathrm{TiO}_{2}$ nanosheets from hybrid functional calculations. Mater. Chem. Phys. 2017, 186, 333-340. [CrossRef]

33. Gao, H.; Hu, G.; Sui, J.; Mu, C.; Shangguan, W.; Kong, M.; Shentu, W. Scalable preparation of defect-rich free-standing $\mathrm{TiO}_{2}$ sheets with visible-light photocatalytic activity. Appl. Catal. B Environ. 2018, 226, 337-345. [CrossRef]

34. Vorontsov, A.V.; Smirniotis, P.G. Structure, electronic and optical properties of bilayer anatase nanoribbons. Comput. Mater. Sci. 2018, 155, 266-281. [CrossRef]

35. Vorontsov, A.V.; Valdés, H. Quantum size effect and visible light activity of anatase nanosheet quantum dots. J. Photochem. Photobiol. Chem. 2019, 379, 39-46. [CrossRef]

36. Wang, L.; Wei, D.; Kang, S.; Xie, X.; Shi, Y.; Liu, S. Two-Dimensional Titania: Structures and Properties Predicted by First Principle Calculation. J. Phys. Chem. C 2018, 122, 22911-22919. [CrossRef]

37. Haick, H.; Paz, Y. Long-Range Effects of Noble Metals on the Photocatalytic Properties of Titanium Dioxide. J. Phys. Chem. B 2003, 107, 2319-2326. [CrossRef]

38. Li, C.; Wang, H.; Lu, D.; Wu, W.; Ding, J.; Zhao, X.; Xiong, R.; Yang, M.; Wu, P.; Chen, F.; et al. Visible-lightdriven water splitting from dyeing wastewater using Pt surface-dispersed $\mathrm{TiO}_{2}$-based nanosheets. J. Alloys Compd. 2017, 699, 183-192. [CrossRef]

39. Uner, D. The Effect of Addition of Pt on the Gas Phase Photocatalysis over $\mathrm{TiO}_{2}$. In Environmentally Benign Photocatalysts; Anpo, M., Kamat, P.V., Eds.; Springer: New York, NY, USA, 2010; pp. 479-501. ISBN 978-0-387-48441-9.

40. Falconer, J.L.; Magrini-Bair, K.A. Photocatalytic and Thermal Catalytic Oxidation of Acetaldehyde on $\mathrm{Pt} / \mathrm{TiO} 2$. J. Catal. 1998, 179, 171-178. [CrossRef]

41. Shinde, Y.; Wadhai, S.; Ponkshe, A.; Kapoor, S.; Thakur, P. Decoration of Pt on the metal free $\mathrm{RGO}^{-\mathrm{TiO}} 2$ composite photocatalyst for the enhanced photocatalytic hydrogen evolution and photocatalytic degradation of pharmaceutical pollutant $\beta$ blocker. Int. J. Hydrog. Energy 2018, 43, 4015-4027. [CrossRef]

42. Wei, Y.; Wu, X.; Zhao, Y.; Wang, L.; Zhao, Z.; Huang, X.; Liu, J.; Li, J. Efficient photocatalysts of $\mathrm{TiO}_{2}$ nanocrystals-supported PtRu alloy nanoparticles for $\mathrm{CO}_{2}$ reduction with $\mathrm{H}_{2} \mathrm{O}$ : Synergistic effect of Pt-Ru. Appl. Catal. B Environ. 2018, 236, 445-457. [CrossRef]

43. Zhao, Y.; Wei, Y.; Wu, X.; Zheng, H.; Zhao, Z.; Liu, J.; Li, J. Graphene-wrapped Pt/TiO 2 photocatalysts with enhanced photogenerated charges separation and reactant adsorption for high selective photoreduction of $\mathrm{CO}_{2}$ to $\mathrm{CH}_{4}$. Appl. Catal. B Environ. 2018, 226, 360-372. [CrossRef]

44. Yang, L.; Wang, W.; Jiang, H.; Zhang, Q.; Shan, H.; Zhang, M.; Zhu, K.; Lv, J.; He, G.; Sun, Z. Improved SERS performance of single-crystalline $\mathrm{TiO}_{2}$ nanosheet arrays with coexposed $\{001\}$ and $\{101\}$ facets decorated with Ag nanoparticles. Sens. Actuators B Chem. 2017, 242, 932-939. [CrossRef]

45. Li, Z.; Wang, X.; Jia, L.; Xing, X. Reduction of HCHO with OH- on Pt loading anatase $\mathrm{TiO}_{2}(001)$ surface: A DFT calculation. Catal. Commun. 2017, 92, 23-26. [CrossRef]

46. Schlexer, P.; Chen, H.-Y.T.; Pacchioni, G. $\mathrm{CO}_{2}$ Activation and Hydrogenation: A Comparative DFT Study of $\mathrm{Ru}_{10} / \mathrm{TiO}_{2}$ and $\mathrm{Cu}_{10} / \mathrm{TiO}_{2}$ Model Catalysts. Catal. Lett. 2017, 147, 1871-1881. [CrossRef]

47. Schvval, A.B.; Juan, A.; Cabeza, G.F. Theoretical study of the role of the interface of Ag4 nanoclusters deposited on $\mathrm{TiO}_{2}(110)$ and $\mathrm{TiO}_{2}$ (101). Appl. Surf. Sci. 2019, 490, 343-351. [CrossRef]

48. Singhal, N.; Ali, A.; Vorontsov, A.; Pendem, C.; Kumar, U. Efficient approach for simultaneous $\mathrm{CO}$ and $\mathrm{H}_{2}$ production via photoreduction of $\mathrm{CO}_{2}$ with water over copper nanoparticles loaded $\mathrm{TiO}_{2}$. Appl. Catal. Gen. 2016, 523, 107-117. [CrossRef]

49. Li, M.; Chen, Y.; Li, W.; Li, X.; Tian, H.; Wei, X.; Ren, Z.; Han, G. Ultrathin Anatase $\mathrm{TiO}_{2}$ Nanosheets for High-Performance Photocatalytic Hydrogen Production. Small 2017, 13, 1604115. [CrossRef] 
50. Li, J.; Zhou, H.; Zhuo, H.; Wei, Z.; Zhuang, G.; Zhong, X.; Deng, S.; Li, X.; Wang, J. Oxygen vacancies on $\mathrm{TiO}_{2}$ promoted the activity and stability of supported Pd nanoparticles for the oxygen reduction reaction. J. Mater. Chem. A 2018, 6, 2264-2272. [CrossRef]

51. Barbieriková, Z.; Dvoranová, D.; Brezová, V.; Džunuzović, E.; Sredojević, D.N.; Lazić, V.; Nedeljković, J.M. Visible-light-responsive surface-modified $\mathrm{TiO}_{2}$ powder with 4-chlorophenol: A combined experimental and DFT study. Opt. Mater. 2019, 89, 237-242. [CrossRef]

52. Vorontsov, A.V.; Smirniotis, P.G. Benchmarking semiempirical and DFT methods for the interaction of thiophene and diethyl sulfide molecules with a $\mathrm{Ti}(\mathrm{OH}) 4\left(\mathrm{H}_{2} \mathrm{O}\right)$ cluster. J. Mol. Model. 2017, 23, 223. [CrossRef]

53. Geldof, D.; Tassi, M.; Carleer, R.; Adriaensens, P.; Roevens, A.; Meynen, V.; Blockhuys, F. Binding modes of phosphonic acid derivatives adsorbed on $\mathrm{TiO}_{2}$ surfaces: Assignments of experimental IR and NMR spectra based on DFT/PBC calculations. Surf. Sci. 2017, 655, 31-38. [CrossRef]

54. Quintero, Y.C.; Nagarajan, R. Molecular and dissociative adsorption of DMMP, Sarin and Soman on dry and wet $\mathrm{TiO}_{2}(110)$ using density functional theory. Surf. Sci. 2018, 675, 26-35. [CrossRef]

55. Trubitsyn, D.A.; Vorontsov, A.V. Molecular and reactive adsorption of dimethyl methylphosphonate over (001) and (100) anatase clusters. Comput. Theor. Chem. 2013, 1020, 63-71. [CrossRef]

56. Rudshteyn, B.; Negre, C.F.A.; Oliboni, R.S.; Monti, A.; Chen, J.; Crabtree, R.H.; Rego, L.G.C.; Batista, V.S. Inferring Protonation States of Hydroxamate Adsorbates on $\mathrm{TiO}_{2}$ Surfaces. J. Phys. Chem. C 2017, 121, 11985-11990. [CrossRef]

57. Setvin, M.; Hulva, J.; Wang, H.; Simschitz, T.; Schmid, M.; Parkinson, G.S.; Di Valentin, C.; Selloni, A.; Diebold, U. Formaldehyde Adsorption on the Anatase $\mathrm{TiO}_{2}$ (101) Surface: Experimental and Theoretical Investigation. J. Phys. Chem. C 2017, 121, 8914-8922. [CrossRef]

58. Vorontsov, A.V. Structural and electronic effects in acetone adsorption over $\mathrm{TiO}_{2}$ anatase clusters as the first stage of photocatalytic oxidation. J. Nanoparticle Res. 2017, 19, 326. [CrossRef]

59. Li, F.; Huang, W.-H.; Gong, X.-Q. Unique adsorption behaviors of $\mathrm{NO}$ and $\mathrm{O}_{2}$ at hydrogenated anatase $\mathrm{TiO}_{2}$ (101). Chin. Chem. Lett. 2018, 29, 765-768. [CrossRef]

60. Lang, X.; Liang, Y.; Sun, L.; Zhou, S.; Lau, W.-M. Interplay between Methanol and Anatase $\mathrm{TiO}_{2}$ (101) Surface: The Effect of Subsurface Oxygen Vacancy. J. Phys. Chem. C 2017, 121, 6072-6080. [CrossRef]

61. Nadeem, I.M.; Harrison, G.T.; Wilson, A.; Pang, C.L.; Zegenhagen, J.; Thornton, G. Bridging Hydroxyls on Anatase $\mathrm{TiO}_{2}$ (101) by Water Dissociation in Oxygen Vacancies. J. Phys. Chem. B 2018, 122, 834-839. [CrossRef]

62. Chen, K.; Chen, C.; Ren, X.; Alsaedi, A.; Hayat, T. Interaction mechanism between different facet $\mathrm{TiO}_{2}$ and U(VI): Experimental and density-functional theory investigation. Chem. Eng. J. 2019, 359, 944-954. [CrossRef]

63. Zhang, J.; Liao, J.; Yang, F.; Xu, M.; Lin, S. Regulation of the Electroanalytical Performance of Ultrathin Titanium Dioxide Nanosheets toward Lead Ions by Non-Metal Doping. Nanomaterials 2017, 7, 327. [CrossRef] [PubMed]

64. Liao, J.; Yang, F.; Wang, C.-Z.; Lin, S. The crystal facet-dependent electrochemical performance of $\mathrm{TiO}_{2}$ nanocrystals for heavy metal detection: Theoretical prediction and experimental proof. Sens. Actuators $B$ Chem. 2018, 271, 195-202. [CrossRef]

65. Gao, Y.; Lockart, M.; Kispert, L.D.; Bowman, M.K. Photoinduced Charge Separation in Retinoic Acid on $\mathrm{TiO}_{2}$ : Comparison of Three Anchoring Modes. J. Phys. Chem. C 2019, 123, 24634-24642. [CrossRef]

66. Liang, Y.; Yang, Y.; Zhou, H.; Zou, C.; Xu, K.; Luo, X.; Yu, T.; Zhang, W.; Liu, Y.; Yuan, C. A systematic study on the crystal facets-dependent gas sensing properties of anatase $\mathrm{TiO}_{2}$ with designed $\{010\},\{101\}$ and $\{001\}$ facets. Ceram. Int. 2019, 45, 6282-6290. [CrossRef]

67. Zhou, Z.; Yu, Y.; Ding, Z.; Zuo, M.; Jing, C. Modulating High-Index Facets on Anatase $\mathrm{TiO}_{2}$ : Modulating High-Index Facets on Anatase $\mathrm{TiO}_{2}$. Eur. J. Inorg. Chem. 2018, 2018, 683-693. [CrossRef]

68. Di Liberto, G.; Tosoni, S.; Pacchioni, G. Nitrogen doping in coexposed (001)-(101) anatase $\mathrm{TiO}_{2}$ surfaces: A DFT study. Phys. Chem. Chem. Phys. 2019, 21, 21497-21505. [CrossRef]

69. Sasani, A.; Baktash, A.; Mirabbaszadeh, K.; Khoshnevisan, B. Structural and electronic properties of Mg and Mg-Nb co-doped $\mathrm{TiO}_{2}$ (101) anatase surface. Appl. Surf. Sci. 2016, 384, 298-303. [CrossRef]

70. Hiremath, V.; Shavi, R.; Seo, J.G. Controlled oxidation state of $\mathrm{Ti}$ in $\mathrm{MgO}-\mathrm{TiO}_{2}$ composite for $\mathrm{CO}_{2}$ capture. Chem. Eng. J. 2017, 308, 177-183. [CrossRef]

71. Shakir, S.; Abd-ur-Rehman, H.M.; Yunus, K.; Iwamoto, M.; Periasamy, V. Fabrication of un-doped and magnesium doped $\mathrm{TiO}_{2}$ films by aerosol assisted chemical vapor deposition for dye sensitized solar cells. J. Alloys Compd. 2018, 737, 740-747. [CrossRef] 
72. Olowoyo, J.O.; Kumar, M.; Singhal, N.; Jain, S.L.; Babalola, J.O.; Vorontsov, A.V.; Kumar, U. Engineering and modeling the effect of $\mathrm{Mg}$ doping in $\mathrm{TiO}_{2}$ for enhanced photocatalytic reduction of $\mathrm{CO}_{2}$ to fuels. Catal. Sci. Technol. 2018, 8, 3686-3694. [CrossRef]

73. Xing, Z.; Li, Z.; Wu, X.; Wang, G.; Zhou, W. In-situ S-doped porous anatase $\mathrm{TiO}_{2}$ nanopillars for high-efficient visible-light photocatalytic hydrogen evolution. Int. J. Hydrog. Energy 2016, 41, 1535-1541. [CrossRef]

74. Xiong, Y.; He, D.; Jaber, R.; Cameron, P.J.; Edler, K.J. Sulfur-Doped Cubic Mesostructured Titania Films for Use as a Solar Photocatalyst. J. Phys. Chem. C 2017, 121, 9929-9937. [CrossRef]

75. Yan, X.; Yuan, K.; Lu, N.; Xu, H.; Zhang, S.; Takeuchi, N.; Kobayashi, H.; Li, R. The interplay of sulfur doping and surface hydroxyl in band gap engineering: Mesoporous sulfur-doped $\mathrm{TiO}_{2}$ coupled with magnetite as a recyclable, efficient, visible light active photocatalyst for water purification. Appl. Catal. B Environ. 2017, 218, 20-31. [CrossRef]

76. Vorontsov, A.V.; Valdés, H. Insights into the visible light photocatalytic activity of S-doped hydrated $\mathrm{TiO}_{2}$. Int. J. Hydrog. Energy 2019, 44, 17963-17973. [CrossRef]

77. Vorontsov, A.V. Molecular and dissociative adsorption of a diethylsulfide molecule on (010) and (001) faces of a $\mathrm{TiO}_{2}$ anatase nanoparticle. J. Struct. Chem. 2015, 56, 813-822. [CrossRef]

78. Zhou, W.-Y.; Liu, J.-Y.; Song, J.-Y.; Li, J.-J.; Liu, J.-H.; Huang, X.-J. Surface-Electronic-State-Modulated, Single-Crystalline (001) $\mathrm{TiO}_{2}$ Nanosheets for Sensitive Electrochemical Sensing of Heavy-Metal Ions. Anal. Chem. 2017, 89, 3386-3394. [CrossRef]

79. Xiong, F.; Yin, L.-L.; Wang, Z.; Jin, Y.; Sun, G.; Gong, X.-Q.; Huang, W. Surface Reconstruction-Induced Site-Specific Charge Separation and Photocatalytic Reaction on Anatase $\mathrm{TiO}_{2}$ (001) Surface. J. Phys. Chem. C 2017, 121, 9991-9999. [CrossRef]

80. Cao, Y.; Li, Q.; Li, C.; Li, J.; Yang, J. Surface heterojunction between (001) and (101) facets of ultrafine anatase $\mathrm{TiO}_{2}$ nanocrystals for highly efficient photoreduction $\mathrm{CO}_{2}$ to $\mathrm{CH}_{4}$. Appl. Catal. B Environ. 2016, 198, 378-388. [CrossRef]

81. Lei, Y.; Lu, X. Reversing the Photocatalytic Activity Orders of Anatase $\mathrm{TiO}_{2}$ Facets by Surface Treatment. ChemistrySelect 2016, 1, 5838-5841. [CrossRef]

82. Chen, M.; Ma, J.; Zhang, B.; He, G.; Li, Y.; Zhang, C.; He, H. Remarkable synergistic effect between $\{001\}$ facets and surface $\mathrm{F}$ ions promoting hole migration on anatase $\mathrm{TiO}_{2}$. Appl. Catal. B Environ. 2017, 207, 397-403. [CrossRef]

83. Jiang, L.; Sun, L.; Yang, D.; Zhang, J.; Li, Y.-J.; Zou, K.; Deng, W.-Q. Niobium-Doped (001)-Dominated Anatase $\mathrm{TiO}_{2}$ Nanosheets as Photoelectrode for Efficient Dye-Sensitized Solar Cells. ACS Appl. Mater. Interfaces 2017, 9, 9576-9583. [CrossRef] [PubMed]

84. Ma, S.; Song, W.; Liu, B.; Zhong, W.; Deng, J.; Zheng, H.; Liu, J.; Gong, X.-Q.; Zhao, Z. Facet-dependent photocatalytic performance of $\mathrm{TiO}_{2}$ : A DFT study. Appl. Catal. B Environ. 2016, 198, 1-8. [CrossRef]

85. Setvin, M.; Shi, X.; Hulva, J.; Simschitz, T.; Parkinson, G.S.; Schmid, M.; Di Valentin, C.; Selloni, A.; Diebold, U. Methanol on Anatase $\mathrm{TiO}_{2}$ (101): Mechanistic Insights into Photocatalysis. ACS Catal. 2017, 7, 7081-7091. [CrossRef]

86. Li, J.; Zhang, M.; Guan, Z.; Li, Q.; He, C.; Yang, J. Synergistic effect of surface and bulk single-electron-trapped oxygen vacancy of $\mathrm{TiO}_{2}$ in the photocatalytic reduction of $\mathrm{CO}_{2}$. Appl. Catal. B Environ. 2017, 206, 300-307. [CrossRef]

87. Wang, L.; Song, W.; Deng, J.; Zheng, H.; Liu, J.; Zhao, Z.; Gao, M.; Wei, Y. Facet-dependent photocatalytic decomposition of $\mathrm{N}_{2} \mathrm{O}$ on the anatase $\mathrm{TiO}_{2}$ : A DFT study. Nanoscale 2018, 10, 6024-6038. [CrossRef] [PubMed]

88. Ji, Y.; Luo, Y. New Mechanism for Photocatalytic Reduction of $\mathrm{CO}_{2}$ on the Anatase $\mathrm{TiO}_{2}$ (101) Surface: The Essential Role of Oxygen Vacancy. J. Am. Chem. Soc. 2016, 138, 15896-15902. [CrossRef] [PubMed]

89. Naldoni, A.; Altomare, M.; Zoppellaro, G.; Liu, N.; Kment, Š.; Zbořil, R.; Schmuki, P. Photocatalysis with Reduced $\mathrm{TiO}_{2}$ : From Black $\mathrm{TiO}_{2}$ to Cocatalyst-Free Hydrogen Production. ACS Catal. 2019, 9, 345-364. [CrossRef]

90. Dong, G.; Wang, X.; Chen, Z.; Lu, Z. Enhanced Photocatalytic Activity of Vacuum-activated $\mathrm{TiO}_{2}$ Induced by Oxygen Vacancies. Photochem. Photobiol. 2018, 94, 472-483. [CrossRef]

91. Hou, L.; Zhang, M.; Guan, Z.; Li, Q.; Yang, J. Effect of annealing ambience on the formation of surface/bulk oxygen vacancies in $\mathrm{TiO}_{2}$ for photocatalytic hydrogen evolution. Appl. Surf. Sci. 2018, 428, 640-647. [CrossRef] 
92. Wan, P.; Hood, Z.D.; Adhikari, S.P.; Xu, Y.; Yang, S.; Wu, S. Enhancing the photoresponse and photocatalytic properties of $\mathrm{TiO}_{2}$ by controllably tuning defects across $\{101\}$ facets. Appl. Surf. Sci. 2018, 434, 711-716. [CrossRef]

93. Li, J.-J.; Cai, S.-C.; Yu, E.-Q.; Weng, B.; Chen, X.; Chen, J.; Jia, H.-P.; Xu, Y.-J. Efficient infrared light promoted degradation of volatile organic compounds over photo-thermal responsive $\mathrm{Pt}$-rGO-TiO ${ }_{2}$ composites. Appl. Catal. B Environ. 2018, 233, 260-271. [CrossRef]

94. Li, X.; Shen, R.; Ma, S.; Chen, X.; Xie, J. Graphene-based heterojunction photocatalysts. Appl. Surf. Sci. 2018, 430, 53-107. [CrossRef]

95. Martins, P.M.; Ferreira, C.G.; Silva, A.R.; Magalhães, B.; Alves, M.M.; Pereira, L.; Marques, P.A.A.P.; Melle-Franco, M.; Lanceros-Méndez, S. $\mathrm{TiO}_{2} /$ graphene and $\mathrm{TiO}_{2} /$ graphene oxide nanocomposites for photocatalytic applications: A computer modeling and experimental study. Compos. Part B Eng. 2018, 145, 39-46. [CrossRef]

96. Olowoyo, J.O.; Kumar, M.; Singh, B.; Oninla, V.O.; Babalola, J.O.; Valdés, H.; Vorontsov, A.V.; Kumar, U. Self-assembled reduced graphene oxide- $\mathrm{TiO}_{2}$ nanocomposites: Synthesis, DFTB+ calculations, and enhanced photocatalytic reduction of $\mathrm{CO}_{2}$ to methanol. Carbon 2019, 147, 385-397. [CrossRef]

97. Piskorz, W. Attaching titania clusters of various size to reduced graphene oxide and its impact on the conceivable photocatalytic behavior of the junctions-A DFT/D + U and TD DFTB modeling. J. Phys. 2019, 31, 404001. [CrossRef] [PubMed]

98. Meng, A.; Zhang, J.; Xu, D.; Cheng, B.; Yu, J. Enhanced photocatalytic $\mathrm{H}_{2}$-production activity of anatase $\mathrm{TiO}_{2}$ nanosheet by selectively depositing dual-cocatalysts on $\{101\}$ and $\{001\}$ facets. Appl. Catal. B Environ. 2016, 198, 286-294. [CrossRef]

99. Berger, T.; Sterrer, M.; Diwald, O.; Knözinger, E.; Panayotov, D.; Thompson, T.L.; Yates, J.T. Light-Induced Charge Separation in Anatase $\mathrm{TiO}_{2}$ Particles. J. Phys. Chem. B 2005, 109, 6061-6068. [CrossRef]

100. Wilke, K.; Breuer, H.D. The influence of transition metal doping on the physical and photocatalytic properties of titania. J. Photochem. Photobiol. Chem. 1999, 121, 49-53. [CrossRef]

101. Paz, Y. Transient IR spectroscopy as a tool for studying photocatalytic materials. J. Phys. Condens. Matter 2019, 31, 503004. [CrossRef]

102. Serpone, N.; Lawless, D.; Khairutdinov, R.; Pelizzetti, E. Subnanosecond Relaxation Dynamics in $\mathrm{TiO}_{2}$ Colloidal Sols (Particle Sizes Rp = $1.0-13.4 \mathrm{~nm}$ ). Relevance to Heterogeneous Photocatalysis. J. Phys. Chem. 1995, 99, 16655-16661. [CrossRef]

103. Bahnemann, D.W.; Hilgendorff, M.; Memming, R. Charge Carrier Dynamics at $\mathrm{TiO}_{2}$ Particles: Reactivity of Free and Trapped Holes. J. Phys. Chem. B 1997, 101, 4265-4275. [CrossRef]

104. Lawless, D.; Serpone, N.; Meisel, D. Role of hydroxyl radicals and trapped holes in photocatalysis. A pulse radiolysis study. J. Phys. Chem. 1991, 95, 5166-5170. [CrossRef]

105. Schneider, J.; Matsuoka, M.; Takeuchi, M.; Zhang, J.; Horiuchi, Y.; Anpo, M.; Bahnemann, D.W. Understanding $\mathrm{TiO}_{2}$ Photocatalysis: Mechanisms and Materials. Chem. Rev. 2014, 114, 9919-9986. [CrossRef] [PubMed]

106. Paul, S.; Choudhury, A. Investigation of the optical property and photocatalytic activity of mixed phase nanocrystalline titania. Appl. Nanosci. 2014, 4, 839-847. [CrossRef]

107. Bahnemann, D.; Henglein, A.; Lilie, J.; Spanhel, L. Flash photolysis observation of the absorption spectra of trapped positive holes and electrons in colloidal titanium dioxide. J. Phys. Chem. 1984, 88, 709-711. [CrossRef]

108. Yamakata, A.; Ishibashi, T.; Onishi, H. Time-resolved infrared absorption spectroscopy of photogenerated electrons in platinized $\mathrm{TiO}_{2}$ particles. Chem. Phys. Lett. 2001, 333, 271-277. [CrossRef]

109. Yamakata, A.; Ishibashi, T.; Onishi, H. Water- and Oxygen-Induced Decay Kinetics of Photogenerated Electrons in $\mathrm{TiO}_{2}$ and $\mathrm{Pt} / \mathrm{TiO}_{2}$ : A Time-Resolved Infrared Absorption Study. J. Phys. Chem. B 2001, 105, 7258-7262. [CrossRef]

110. De Sario, P.A.; Pietron, J.J.; Taffa, D.H.; Compton, R.; Schünemann, S.; Marschall, R.; Brintlinger, T.H.; Stroud, R.M.; Wark, M.; Owrutsky, J.C.; et al. Correlating Changes in Electron Lifetime and Mobility on Photocatalytic Activity at Network-Modified $\mathrm{TiO}_{2}$ Aerogels. J. Phys. Chem. C 2015, 119, 17529-17538. [CrossRef]

(C) 2020 by the authors. Licensee MDPI, Basel, Switzerland. This article is an open access article distributed under the terms and conditions of the Creative Commons Attribution (CC BY) license (http://creativecommons.org/licenses/by/4.0/). 